\title{
ATIVIDADE ANTIMICROBIANA DE QUITOSANAS E SEUS DERIVADOS: INFLUENCIA DAS CARACTERÍSTICAS ESTRUTURAIS
}

\author{
Juliana B. Macedo ${ }^{a}$, Rafaela C. Sanfelice ${ }^{\mathrm{b}}$, Luiza A. Mercante ${ }^{\mathrm{c}}$, Danilo Martins dos Santos ${ }^{\mathrm{d}}$, Filipe Habitzreuter ${ }^{\mathrm{e}}$, Sérgio \\ Paulo Campana-Filho e Adriana Pavinatto ${ }^{\mathrm{a}, *, 10}$ \\ anstituto Científico e Tecnológico, Universidade Brasil, 08230-030 São Paulo - SP, Brasil \\ 'Instituto de Ciência e Tecnologia, Universidade Federal de Alfenas, 37715-400 Poços de Caldas - MG, Brasil \\ 'Instituto de Química, Universidade Federal da Bahia, 40170-115 Salvador - BA, Brasil \\ ${ }^{\mathrm{d} E m b r a p a ~ I n s t r u m e n t a c ̧ a ̃ o, ~ 13560-970 ~ S a ̃ o ~ C a r l o s ~-~ S P, ~ B r a s i l ~}$ \\ 'enstituto de Química de São Carlos, Universidade de São Paulo, 13560-970 São Carlos - SP, Brasil
}

Recebido em 25/10/2021; aceito em 09/12/2021; publicado na web em 16/02/2022

\begin{abstract}
ANTIMICROBIAL ACTIVITY OF CHITOSAN AND ITS DERIVATIVES: INFLUENCE OF ITS STRUCTURAL CHARACTERISTICS. In recent years, there has been an increasing interest in the development of antimicrobial materials for different applications, especially in the biomedical field. In this context, chitosan is one of the most employed materials due to its highly attractive properties, such as biocompatibility, biodegradability, non-toxicity, and antimicrobial activity against gram-negative and gram-positive bacteria and fungi. In this review, we discuss the different methods used to obtain chitosan and point out how they affect the structural and chemical properties of this material, followed by a detailed discussion on how these properties influence its antimicrobial activities. Additionally, we summarize the most accepted antimicrobial mechanisms of action for chitosans. Specifically, we aim to provide a comprehensive overview on the last findings and progress reported in the literature on the factors that influence the antimicrobial activity of chitosan, e.g., polymeric average molecular weight $(\overline{M W})$, average degree of acetylation $(\overline{D A})$, water-soluble derivatization and sample degree of purity. The data available in the literature indicate that in addition to the structural properties, the effectiveness of such antimicrobial activity of chitosan is also dependent on the target microorganisms. This review will help researchers to better understand the mechanism of action of chitosan against microorganisms based on its structural characteristics.
\end{abstract}

Keywords: chitosan; antimicrobial mechanisms; source; average acetylation degree; molecular weight.

\section{INTRODUÇÃO}

A quitosana é um polissacarídeo de cadeias lineares encontrado na natureza em pequenas quantidades que atua em funções estruturais de membranas celulares de alguns fungos e leveduras. Apesar de estar disponível na natureza, sua principal forma de obtenção é através da reação de desacetilação parcial (ou total, o que é raramente conseguido) da quitina, um polissacarídeo que também tem função estrutural e é encontrado como principal constituinte do exoesqueleto de invertebrados, tais como crustáceos, moluscos, anelídeos e celenterados, podendo ainda estar presente em insetos e na composição da parede celular de fungos e leveduras. ${ }^{1-4}$ Embora ambos os polissacarídeos sejam constituídos por unidades 2-amino2-desoxi-D-glucopiranose (GlcN) e 2-acetamido-2-desoxi-Dglucopiranose (GlcNAc), unidas por ligações glicosídicas do tipo $\beta$ $(1 \rightarrow 4)$ (Figura 1), na quitosana há a predominância de grupos GlcN, enquanto que na quitina os grupos GlcNAc prevalecem.

De modo geral, a presença de vários grupos acetilamina $\left(-\mathrm{NHCOCH}_{3}\right)$ faz com que a quitina seja insolúvel em água e na maioria dos solventes orgânicos comuns devido ao alto grau de empacotamento das cadeias poliméricas, o que acaba por limitar seu uso. Por outro lado, a conversão de grupos acetamida em grupos amina $\left(-\mathrm{NH}_{2}\right)$ confere à quitosana solubilidade em solução aquosa diluída de ácidos (por exemplo, ácidos acético e clorídrico) por conta da protonação do grupo amina, o que leva à formação de um íon amônio $\left.\left(-\mathrm{NH}_{3}^{+}\right)\right)^{1,5,6}$

A extração da quitina e posterior derivatização em quitosana podem ser realizadas através de vários processos químicos ou

*e-mail: adrianapavinatto@gmail.com

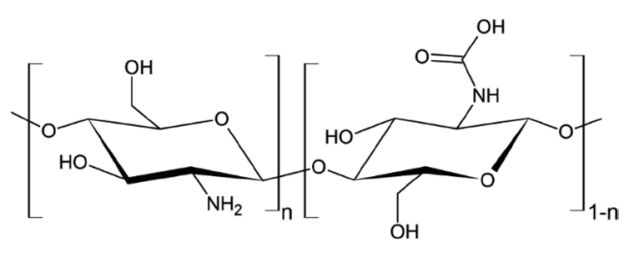

(A)

(B)

Figura 1. Representação esquemática da estrutura química das unidades repetitivas de quitina e quitosana, (A) GlcN e (B) GlcNAc

biológicos, os quais serão abordados nesta revisão. A fonte de matéria-prima, bem como os processos empregados na obtenção da quitosana, exercem forte influência nas características estruturais que regem as propriedades físico-químicas e biológicas desse polímero, a saber, massa molar média $(\overline{M M})$, índice de polidispersão (PDI), grau médio de acetilação $(\overline{G A})$, o qual é correspondente ao número médio de unidades GlcNAc na cadeia polimérica, e parâmetro de acetilação, o qual indica a sequência de distribuição dos grupos GlcNAc e GlcN nas cadeias de quitosana. O termo "quitosanas" é frequentemente utilizado e refere-se às diferentes características estruturais que o polissacarídeo pode apresentar, uma vez que o polímero não possui uma estrutura única e definida. Tais características dependem, principalmente, da fonte de obtenção e do processo de extração e acarretam diferentes propriedades físico-químicas e biológicas, permitindo vasta aplicação nas mais diversas áreas. ${ }^{7}$

Propriedades como baixa toxicidade, biodegradabilidade e biocompatibilidade, assim como atividade antioxidante e antimicrobiana, fazem das quitosanas promissores polímeros para aplicações em diversas áreas, incluindo as áreas de biotecnologia, ${ }^{8}$ 
medicina, ${ }^{9,10}$ cosmética ${ }^{11,12}$ e agricultura. ${ }^{13-16}$ Dentre essas propriedades, é descrito na literatura um largo espectro de ação antimicrobiana das quitosanas, tais como forte atividade bactericida, atividade bacteriostática contra bactérias gram-positivas $(\mathrm{G}+)$ e gram-negativas (G-) e ação frente a fungos e leveduras. ${ }^{17,18}$ Apesar do mecanismo real de inibição ainda não ser totalmente compreendido, sabe-se que as características estruturais das quitosanas podem influenciar no mecanismo de ação de grupos de micro-organismos específicos, demandando, assim, o controle desses parâmetros para que haja potencialização em suas diversas formas de ação. ${ }^{13,19,20}$

Apesar de diferentes trabalhos na literatura abordarem a atividade antimicrobiana das quitosanas com base em suas características estruturais e propriedades físico-químicas, ${ }^{17,20-24}$ ainda são escassos os estudos que reúnem e comparam tais resultados, relacionando-os com as diversas características estruturais das quitosanas utilizadas. Sendo assim, além de abordar as diferentes formas de obtenção de quitosanas e sua influência nas características estruturais do polissacarídeo, nesta revisão discutiremos evidências científicas sobre a influência dessas características em sua atividade antimicrobiana. Durante a revisão, serão abordados os principais mecanismos de ação propostos para a atividade antimicrobiana das quitosanas e como as variações das principais características estruturais do polímero podem levar a variações do efeito antimicrobiano, de forma a explorar os mecanismos possivelmente associados.

\section{MÉTODOS DE OBTENÇ̃̃O DA QUITOSANA E SUA INFLUÊNCIA NAS CARACTERÍSTICAS ESTRUTURAIS DO POLISSACARÍDEO}

\section{Processos físico-químicos utilizados na produção de quitosanas}

Quitosanas são preparadas em escala industrial, principalmente a partir da quitina extraída de carapaças de caranguejo e cascas de camarão oriundas do processamento de frutos do mar. ${ }^{25}$ Fontes alternativas para a produção industrial da quitina, incluindo insetos ${ }^{26}$ e moluscos,${ }^{27}$ também têm sido amplamente investigadas. Diferentes organismos apresentam diversas proporções mássicas de quitina. Por exemplo, resíduos da casca de crustáceos são, em média, compostos de $30 \%$ a $50 \%$ de massa de carbonato de cálcio e de $20 \%$ a $30 \%{ }^{4,25}$ de massa de quitina, ao passo que os gládios de lulas (Doryteuthis spp.) contêm $35 \%$ a $40 \%$ de quitina, $60 \%$ a $65 \%$ de proteínas e traços de sais inorgânicos. ${ }^{28}$

O processo de extração de quitina envolve uma série de tratamentos químicos sequenciais, como desmineralização, desproteinização e despigmentação, destinados a remover diversos componentes, incluindo minerais, proteínas e pigmentos associados ao polímero, conforme mostrado na Figura $2 .{ }^{25,29}$ Dependendo da fonte de matéria-prima, como, por exemplo, os gládios de lulas, as etapas de desmineralização e despigmentação se tornam desnecessárias devido ao baixo teor de minerais e pigmentos. ${ }^{28}$ Nos casos de carapaças de caranguejos e cascas de camarões, a etapa inicial de extração geralmente consiste na desmineralização, sendo a matériaprima submetida a tratamento com soluções aquosas de diferentes ácidos, tais como $\mathrm{HCl}, \mathrm{HNO}_{3}, \mathrm{H}_{2} \mathrm{SO}_{4}, \mathrm{CH}_{3} \mathrm{COOH}$ e $\mathrm{HCOOH}$, para a remoção de minerais, incluindo carbonatos e fosfatos de cálcio. ${ }^{30,31}$ Os parâmetros que influenciam esse processo são: (i) teor de minerais na matéria-prima; (ii) força do ácido e concentração da solução ácida; (iii) concentração de matéria-prima; e (iv) tempo e temperatura de reação. ${ }^{25,30,32}$ Esses parâmetros devem ser ajustados de modo a proporcionar a máxima remoção de minerais e minimizar a despolimerização da quitina. Nesse sentido, a desmineralização é comumente realizada empregando soluções aquosas de $\mathrm{HCl}(1 \%$ $10 \%$ ) à temperatura ambiente por períodos de 1 a $3 \mathrm{~h}^{25,33}$

A etapa de desproteinização consiste na remoção de proteínas e de outros componentes orgânicos associados à quitina por meio de tratamentos com soluções aquosas de diferentes bases, incluindo $\mathrm{NaOH}, \mathrm{KOH}, \mathrm{Ca}(\mathrm{OH})_{2}, \mathrm{~K}_{2} \mathrm{CO}_{3}, \mathrm{Na}_{2} \mathrm{CO}_{3}$ e $\mathrm{NaHCO}_{3}$. Soluções de $\mathrm{NaOH}(1 \%-10 \%)$ são as mais utilizadas, e o processo de desproteinização é geralmente realizado a temperaturas variando entre 20 e $100{ }^{\circ} \mathrm{C}$ por períodos de 2 a 72 h..$^{25,27,29}$ A concentração da solução alcalina, o tempo e a temperatura da reação devem ser controlados de modo a minimizar a despolimerização e a ocorrência de desacetilação da quitina. Dependendo da biomassa a partir da qual a quitina é extraída, uma etapa adicional posterior à despigmentação se faz necessária por meio de processos de extração com solventes, como etanol $^{34}$ e acetona, ${ }^{35}$ ou por processo de branqueamento utilizando $\mathrm{KMnO}_{4},{ }^{36} \mathrm{NaOCl}^{37}$ ou $\mathrm{H}_{2} \mathrm{O}_{2}{ }^{38}$ Dentre os extratos do processo de despigmentação por solventes está a astaxantina, um pigmento encontrado no exoesqueleto de crustáceos amplamente utilizado nas indústrias alimentícia, farmacêutica e de cosméticos. ${ }^{39}$

Carapaças de camarões/caranguejos

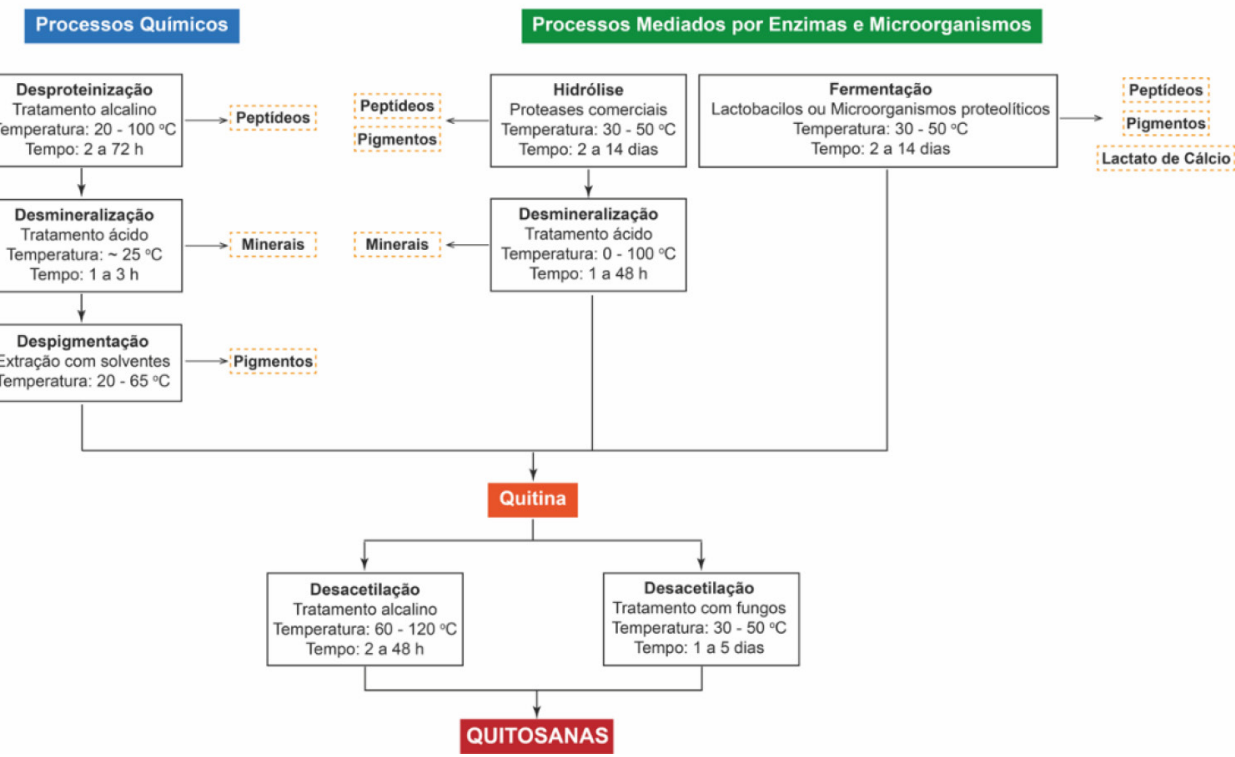

Figura 2. Processos químicos e mediados por enzimas e micro-organismos para a produção de quitina e quitosana 
A conversão de quitina em quitosana ocorre através da reação de $N$-desacetilação, na qual os grupos acetamida nas unidades GlcNAc de quitina são hidrolisados, resultando na formação de uma cadeia polimérica predominantemente constituída de unidades GlcN, ${ }^{27}$ conforme ilustrado na Figura 1. O produto obtido dessa reação é denominado quitosana quando o conteúdo médio de unidades GlcN é superior a $50 \%$ e apresenta solubilidade em soluções aquosas diluídas de ácidos, tais como os ácidos clorídrico e acético. ${ }^{14} \mathrm{~A}$ reação de $N$-desacetilação em escala laboratorial e industrial é frequentemente realizada através do tratamento alcalino da quitina com soluções concentradas de hidróxido de sódio $(40 \%-50 \%)$ a temperaturas elevadas $\left(60-120{ }^{\circ} \mathrm{C}\right) .^{25,29}$ Os principais parâmetros que influenciam esse processo são: (i) a concentração da solução alcalina; (ii) a razão mássica de quitina/solução alcalina; (iii) o tamanho médio das partículas; (iv) a cristalinidade da quitina; (v) o tempo; e (vi) as temperatura reacionais. ${ }^{27,29,40}$ Embora esse processo seja o mais utilizado, a reação ocorre em meio heterogêneo e leva à formação de produtos não uniformes em termos de características estruturais e propriedades físico-químicas.,33 Ademais, apesar do tratamento alcalino resultar na hidrólise parcial dos grupos acetamido das unidades GlcNAc, a tentativa de melhorar a eficiência da reação através do prolongamento do tempo e do aumento da temperatura leva à despolimerização e, consequentemente, à formação de polímeros de baixa massa molar e a um elevado índice de dispersividade..$^{14,27,41}$

Nesse sentido, nas últimas duas décadas diversas estratégias têm sido propostas para minimizar a ocorrência de despolimerização e aumentar a eficiência da reação de $N$-desacetilação da quitina. Dentre os principais métodos desenvolvidos pode-se citar a explosão a vapor, ${ }^{42}$ a irradiação de ultrassom de alta intensidade ${ }^{27} \mathrm{e}$ de micro-ondas ${ }^{37}$ e os tratamentos sucessivos de desacetilação. ${ }^{27,43}$ Independentemente do método utilizado para a desacetilação, os parâmetros reacionais devem ser cuidadosamente controlados, uma vez que afetam as características das quitosanas, incluindo o grau médio de acetilação $(\overline{G A})$, a massa molecular média $(\overline{M M})$ e a distribuição das unidades GlcN e GlcNAc nas cadeias. ${ }^{25,27}$ Essas características, por sua vez, exercem grande influência sobre as propriedades físico-químicas (solubilidade e viscosidade), as atividades biológicas (biodegradabilidade, biocompatibilidade e atividade antimicrobiana) e, consequentemente, as aplicações das quitosanas..$^{13,44}$

\section{Processos mediados por enzimas e micro-organismos}

Os métodos químicos utilizados industrialmente para a extração de quitina possuem algumas desvantagens, notadamente: alto consumo de energia, tempos longos de processamento e elevada geração de resíduos. ${ }^{45,46}$ Essa última ainda apresenta o agravante de os principais resíduos (pigmentos e proteínas) serem de difícil reaproveitamento. ${ }^{35,47}$ Com isso, métodos de extração de quitina mediados por enzimas e micro-organismos vêm sendo propostos como alternativas mais ambientalmente amigáveis (sustentáveis) para efetuar as etapas de desproteinização, desmineralização e despigmentação, conforme ilustrado na Figura 2. ${ }^{48}$ Além disso, quitosanas também podem ser obtidas via desacetilação enzimática da quitina. ${ }^{49}$

Nos processos mediados por enzimas, para a etapa de desproteinização, é comum o uso de proteases, tais como pepsina ${ }^{50}$ e tripsina. ${ }^{51}$ Embora a obtenção de enzimas purificadas seja um processo de alto custo e com baixa eficiência, é possível utilizar proteases derivadas de bactérias ${ }^{52}$ e vísceras de peixes. ${ }^{53}$ Por mais que o tratamento enzimático seja menos eficiente e apresente maiores custos quando comparado ao processo termoquímico realizado em meio fortemente alcalino, ele gera hidrolisado proteico com grande potencial de uso na indústria alimentícia. ${ }^{39,47}$
A extração de quitina da biomassa também pode ser mediada por micro-organismos via processos fermentativos empregando bactérias (Lactobacillus sp., Pseudomonas sp., Bacillus sp.) e fungos (Aspergillus sp.). ${ }^{54}$ Os lactobacilos são responsáveis pela fermentação da biomassa e subsequente produção in situ de ácidos orgânicos (por exemplo, ácidos lático e acético), o que acarreta a diminuição do pH e ativação das proteases presentes no meio. ${ }^{55}$ Como nos processos mediados por enzimas, o uso de lactobacilos leva à formação de uma fase líquida rica em proteínas e pigmentos e uma fase sólida rica em quitina, que pode ser facilmente separada por filtração. É interessante destacar que a desmineralização também ocorre durante este processo, visto que os carbonatos e fosfatos são removidos na presença dos ácidos utilizados. ${ }^{56}$ De modo alternativo, outros micro-organismos capazes de produzir grandes quantidades de proteases podem ser selecionados para a desproteinização. ${ }^{46}$

Tais métodos de extração de quitina, sejam eles mediados por enzimas ou micro-organismos, caracterizam-se pelas condições brandas empregadas, já que as soluções de ácidos e bases utilizadas não são fortes e as temperaturas de processamento estão tipicamente entre 30 e $50{ }^{\circ} \mathrm{C}$. No entanto, as reações podem levar de 7 a 14 dias. ${ }^{57}$ Tais condições tendem a extrair quitinas de elevada massa molecular e com menor grau de dispersividade, além de prevenir a ocorrência de desacetilação. ${ }^{57}$ Embora ainda sejam processos de maior custo quando comparados aos termoquímicos, seu desenvolvimento tem evoluído a partir de estudos que visam avaliar os efeitos de diferentes fatores, principalmente aqueles ligados ao processo de fermentação, tais como $\mathrm{pH}$ inicial, fonte de carbono e sua concentração, temperatura, tempo, tamanho das partículas do substrato e tipo de micro-organismo e das diferentes fontes de biomassa. ${ }^{46,57}$ Portanto, em alguns casos, a eficiência na obtenção de quitina pode ser superior a $90 \% .^{58,59} \mathrm{O}$ uso de consórcios de micro-organismos, que combina as diferentes atividades biológicas das culturas associadas, também pode ser adequado conforme a natureza, vegetal ou animal, da biomassa. Dessa forma, resíduos comuns da indústria alimentícia (por exemplo, soro de leite e melaço) podem ser utilizados como fontes de carbono para que a fermentação ocorra ${ }^{46}$ Como resultado, a quitina pode ser produzida inteiramente a partir de rejeitos das indústrias pesqueira e alimentícia.

\section{Processos biotecnológicos para a produção de quitosanas}

Os processos descritos anteriormente envolvem a extração de quitina e sua posterior conversão em quitosanas a partir de biomassa de procedência marinha, os quais podem ser afetados pela sazonalidade dos animais, bem como pelos elevados custos de produção e controle limitado das propriedades físico-químicas dos produtos. ${ }^{60}$ Dessa forma, processos biotecnológicos de produção de quitosanas a partir do cultivo de fungos vêm sendo estudados com intuito de contornar tais desvantagens.

Fungos dos gêneros Mucor, Aspergillus e Absidia, além da classe dos Zigomicetos, produzem quitina e quitosanas em suas paredes celulares, ${ }^{60}$ cujos teores em massa de quitina variam entre $2 \%$ e $42 \% .{ }^{61,62}$ O cultivo contínuo, independentemente de quaisquer fatores sazonais, e o rigoroso controle das condições de cultivo, juntamente com o emprego de fontes de carbono abundantes e de cepas selecionadas ou geneticamente modificadas para apresentar elevada taxa de crescimento são as principais características dos processos biotecnológicos de produção de quitina e quitosanas. Além disso, os processos de isolamento e separação de quitina e quitosanas são simples, a pureza dos produtos é elevada ${ }^{63} \mathrm{e}$ as características estruturais e físico-químicas são controladas, ${ }^{64}$ garantindo reprodutibilidade das propriedades e superando, assim, as mais importantes limitações das aplicações na indústria, sobretudo a alimentícia, a farmacêutica e a biomédica ${ }^{62}$

$\mathrm{O}$ baixo impacto ambiental dos processos biotecnológicos 
também é relevante, uma vez que eles não demandam grandes quantidades de insumos, tais como água, ácidos e bases fortes, além de não dependerem dos descartes da pesca predatória de animais marinhos. ${ }^{64}$ Ademais, as fontes de carbono utilizadas para o cultivo dos fungos podem ter origem de descartes agroindustriais, como milhocina e manipueira, ${ }^{63,65}$ ampliando o caráter ecologicamente amigável deste tipo de processo.

A desacetilação da quitina para a produção de quitosana ocorre através de enzimas denominadas quitina desacetilases, presentes em fungos como Mucor rouxii ${ }^{66}$ e Aspergillus nidulans. ${ }^{67}$ As quitosanas produzidas tendem a apresentar elevada massa molecular e $\overline{G A}$ bem definido devido à regiosseletividade das enzimas. ${ }^{68}$ Outras enzimas, como quitinases e quitosanases, são responsáveis pela formação de oligômeros de quitosanas com propriedades físico-químicas bem conhecidas, além do controle dos parâmetros de acetilação. ${ }^{69} \mathrm{O}$ isolamento da quitosana a partir dos micélios de fungos ocorre por processos de separação, conforme mostrado na Figura 3..$^{61,64}$

O principal desafio dos métodos biotecnológicos está relacionado à quantidade de quitosanas produzidas. As pesquisas mais recentes têm focado na seleção de espécies de fungos e na otimização das condições de cultivo para viabilizar a produção de quitosana em escala industrial, a fim de competir com os métodos convencionais. Diferentes fontes de carbono e suas concentrações, assim como temperatura e tempo de fermentação, são variáveis comumente estudadas. ${ }^{60,61,63,65}$ Além do cultivo de fungos, os pesquisadores também têm buscado reutilizar os fungos descartados pelas indústrias cervejeiras e de panificação ${ }^{62}$ e discutir o uso de micro-organismos geneticamente modificados. $^{70}$

\section{MECANISMOS DE AÇÃO DA QUITOSANA NA ATIVIDADE ANTIMICROBIANA}

\section{Principais hipóteses do mecanismo de ação da quitosana contra micro-organismos}

A conhecida atividade antimicrobiana das quitosanas contra bactérias G+, G- e fungos é dependente de fatores que incluem o tipo

\section{Biomassa de Fungos}

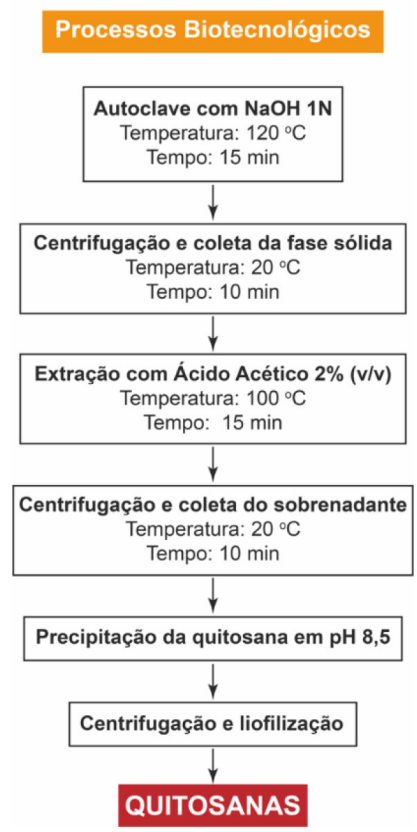

Figura 3. Processo de isolamento de quitosanas obtidas por métodos biotecnológicos de micro-organismo, o $\mathrm{pH}$ do meio, as características estruturais do polímero (massa molecular e grau de acetilação), a fonte de obtenção da quitosana e a concentração de quitosana. ${ }^{20}$ Dentre esses fatores, o pH do meio é um parâmetro crucial para a atividade antimicrobiana desses polissacarídeos por estar intimamente relacionado com a sua solubilidade, uma vez que o grupamento amina $\left(-\mathrm{NH}_{2}\right)$ torna-se carregado positivamente $\left(-\mathrm{NH}_{3}{ }^{+}\right)$em $\mathrm{pH}$ levemente ácidos fazendo com que a quitosana seja mais solúveis e tenham uma melhor atividade antimicrobiana que a quitina. ${ }^{17,18,20,23,44,71-73}$ Nesse sentido, o $\overline{G A}$ das quitosanas infere na determinação da quantidade de cargas positivas presente nas cadeias e, consequentemente, na atividade antimicrobiana do polímero. Além de apresentar carga positiva em soluções aquosas levemente ácidas (acidez muito elevada pode danificar estruturalmente a cadeia polimérica), a quitosana é uma macromolécula, e sua elevada massa molecular média também influencia a atividade microbiológica. ${ }^{44} \mathrm{~A}$ quitosana é capaz de inibir o crescimento de uma ampla variedade de fungos e bactérias, ${ }^{23,44,74,75}$ porém, de forma geral, a sua atividade antifúngica apresenta menor eficiência quando comparada com a atividade antibacteriana.

Diferentes mecanismos vêm sendo propostos para explicar a ação das quitosanas e seus derivados frente aos diferentes microorganismos. De acordo com a literatura, os mecanismos de ação mais aceitos são: (i) alteração da permeabilidade da membrana ou parede celular do micro-organismo, causando seu rompimento; ${ }^{76-78}$ (ii) interação das quitosanas com o DNA do micro-organismo, afetando a síntese de proteínas devido à inibição do mRNA; ${ }^{79-83}$ (iii) quelação de nutrientes (íons metálicos) pelas quitosanas, os quais são essenciais para o crescimento microbiano, ${ }^{84-86}$ ou (iv) formação de um filme polimérico espesso sobre a superfície celular do microorganismo, impedindo trocas gasosas e de nutrientes com o meio externo, levando à morte celular. ${ }^{87,88}$ Além disso, é possível que mais de um desses mecanismos ocorra concomitantemente durante a ação antimicrobiana da quitosana.

Dentre essas hipóteses de mecanismo, o rompimento da membrana celular e a quelação com nutrientes são frequentemente relacionados à interação entre as cargas positivas dos grupos $-\mathrm{NH}_{3}{ }^{+}$das cadeias de quitosanas e às cargas negativas presentes na membrana/ parede celular dos micro-organismos, em que, geralmente, o menor grau de acetilação implica maior atividade das quitosanas contra os micro-organismos. ${ }^{76}$ Já a interação com o DNA do micro-organismo é associada à capacidade de quitosanas com baixa massa molecular em permear para o interior das células. ${ }^{79}$ Por outro lado, a formação de filme polimérico sob a superfície das células, englobando-a e impedindo trocas gasosas e de nutrientes, é frequentemente atribuída ao uso de quitosanas com alta massa molecular. ${ }^{88}$ Além disso, a dependência da $\overline{M M}$ com a atividade das quitosanas pode estar relacionada à estrutura da membrana/parede celular do microorganismo. ${ }^{44,73}$ A Figura 4 representa os diferentes mecanismos de ação das quitosanas e seus derivados frente a micro-organismos.

\section{Atividade antifúngica}

As quitosanas apresentam atividade contra fungos e leveduras, como aqueles dos gêneros Fusarium oxysporum, Botrytis cinerea e Candida lambica. Fungos são micro-organismos que apresentam unidades celulares conhecidas como hifas e que, além da membrana celular, possuem uma camada extra de proteção: a parede celular. A presença da parede celular pode ser um fator determinante para a maior resistência desses micro-organismos à ação de quitosanas, pois para promover o rompimento da célula e a possível entrada do polímero no meio intracelular, as duas barreiras devem ser transpostas. ${ }^{89} \mathrm{~A}$ parede celular é composta, em sua maioria, por polissacarídeos, e sua composição é específica para cada gênero de fungo. ${ }^{89} \mathrm{O}$ mecanismo de 


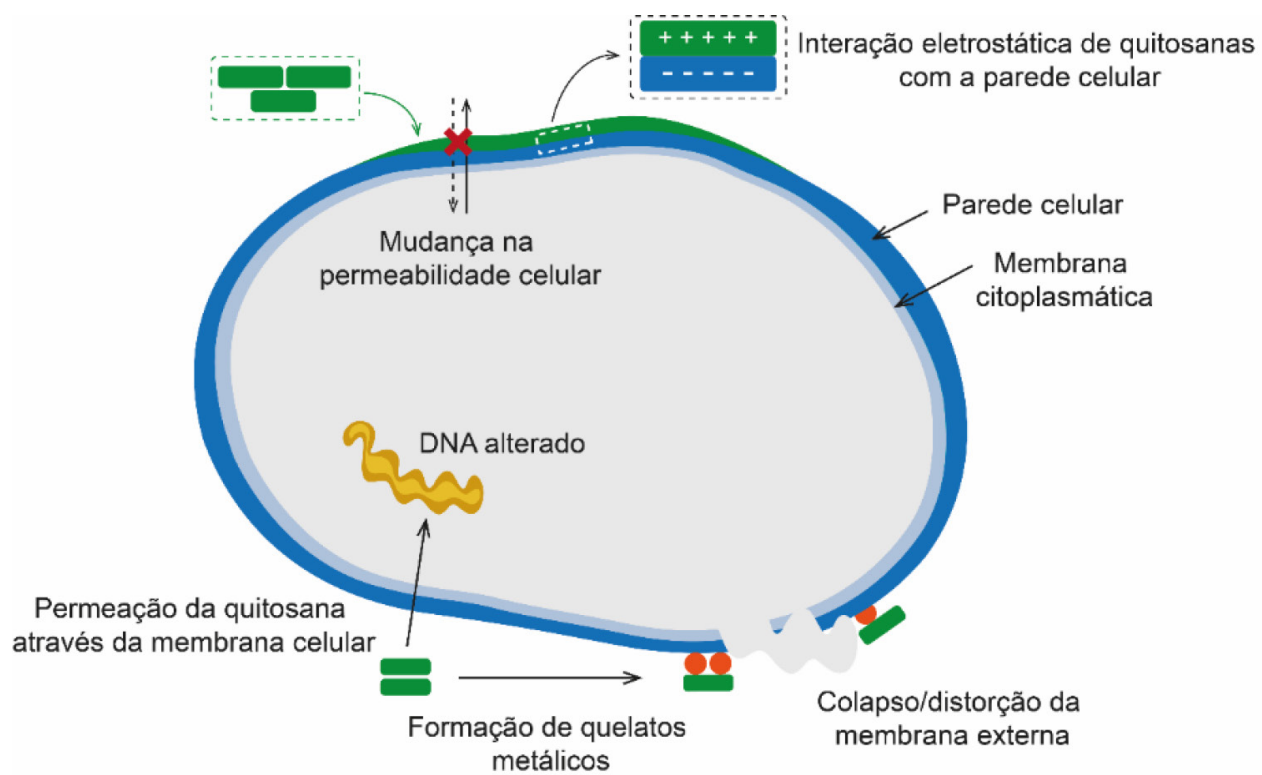

Quitosanas lons metálicos/elementos traço

Figura 4. Representação esquemática dos principais mecanismos de ação das quitosanas frente a micro-organismos

ação frente a esses micro-organismos depende da estrutura da parede celular dos mesmos, que irá interferir diretamente no seu crescimento. $\mathrm{O}$ mecanismo que melhor descreve a ação de materiais à base de quitosanas contra o crescimento de certos tipos de fungos envolve a interação do polímero com a parede celular dos micro-organismos, afetando diretamente o seu crescimento.$^{23}$ Em sinergia, oligômeros de quitosana podem, então, se difundir nas hifas dos fungos, interferindo na atividade das enzimas responsáveis pelo seu crescimento. ${ }^{72}$ Além disso, a intensidade da degradação da parede celular é dependente do $\mathrm{pH}$ do meio, do $\overline{G A}$ das quitosanas e de sua concentração. ${ }^{23,72}$

O trabalho de Pavinatto et al. ${ }^{74}$ descreve a utilização de filmes à base de quitosana como barreira de proteção física e microbiológica de morangos in natura. Observou-se ausência de fungos no fruto recoberto com filmes de quitosana contendo glicerol após 7 dias de armazenamento em temperatura ambiente. Já o fruto usado como controle (sem recobrimento) ficou totalmente recoberto por fungos ao longo desse período. O principal fungo que ataca frutos como o morango é chamado fungo cinza, provocado pelo micro-organismo Botrytics cinerea, um fungo filamentoso da família Sclerotiniaceae. Quando o fruto é exposto a esse micro-organismo, rapidamente ocorre sua colonização, e em pouco tempo todo o fruto é completamente contaminado. Segundo os trabalhos de Hadwiger, ${ }^{90}$ Lee et al. ${ }^{91} \mathrm{e}$ Lopes-Moya et al., ${ }^{92}$ a natureza policatiônica das quitosanas, quando em contato com a parede celular dos fungos, provoca o vazamento de eletrólitos dentro da célula, retardando ou inibindo sua síntese proteica (Figura 5). Resultados similares foram relatados recentemente por Limon et al. ${ }^{93}$ Grande-Tovar et al. ${ }^{94}$ e Al-Najada et al..${ }^{95}$

Meng et al. ${ }^{96}$ reportaram a ação antifúngica de quitosanas frente ao micro-organismo Aspergillus ochraceus. Os autores verificaram uma significativa inibição da germinação de esporos e o crescimento do fungo através de mudanças na morfologia externa e na microestrutura interna do A. ochraceus. Os resultados indicaram que o tratamento com quitosana promoveu a degradação celular através da perturbação da integridade da membrana celular, além da consequente inibição da biogênese do ribossomo, o que poderia explicar a possível ação antifúngica das quitosanas.

Tal ação contra o micro-organismo Alteraria alternata foi reportada no trabalho de Guo et al. ${ }^{97}$ Os resultados obtidos nesse trabalho permitiram aos autores concluir que a quitosana age atacando

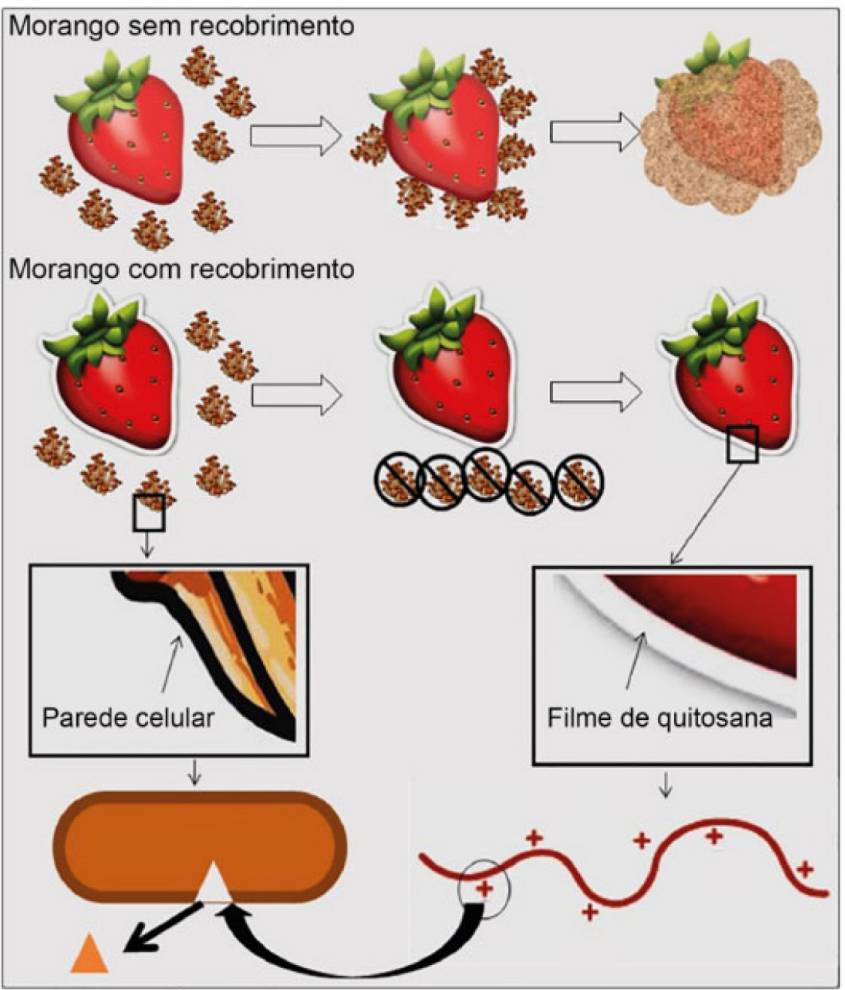

Figura 5. Ilustração esquemática do processo de proteção contra microorganismos em morangos revestidos com filmes de quitosana. Adaptada com permissão da ref. 74. Copyright 2020 ELSEVIER

a parede celular do fungo através da ação das cargas positivas da cadeia polimérica (atração eletrostática), como já foi relatado em outros trabalhos. ${ }^{18,92,95,96,98}$ Os autores utilizaram frutos de jujuba com e sem a inoculação de uma suspensão de quitosana, e a qualidade dos frutos foi acompanhada durante um período de quatro dias. Através dos resultados foi possível observar que o tamanho das lesões nos frutos foi mais pronunciado naqueles que não foram inoculados com a suspensão de quitosana, o que evidenciou a eficácia do polissacarídeo no combate à degradação do fruto por fungos. 


\section{Atividade bactericida}

Estudos recentes relatam que a quitosana apresenta atividade bactericida contra bactérias $\mathrm{G}+$, como Bacillus cereus e Staphylococcus aureus, e bactérias G-, como Salmonella typhimurium e Escherichia coli. ${ }^{20,71,99}$ Do mesmo modo que ocorre com a atividade fungicida, um dos fatores que mais influencia a atividade bactericida de quitosanas é o seu $\overline{G A}$. Diferentes estudos demonstram que quanto menor o $\overline{G A}$, maior é a densidade de carga positiva proporcionada pelo grupo amino protonado nas cadeias e, com isso, maior é a atividade antibacteriana do polímero. ${ }^{100-102}$ Apesar de a maioria dos estudos relatar essa hipótese em relação ao $\overline{G A}$, outros mecanismos têm sido propostos para explicar a atividade bactericida e bacteriostática da quitosana, dependendo não só das características estruturais do polissacarídeo, mas também da composição estrutural do micro-organismo, uma vez que as bactérias G+ e G- diferem quanto à constituição de suas membranas celulares, conforme mostrado na Figura 6A. As membranas das bactérias $\mathrm{G}+$ são formadas por várias camadas de peptidoglicano e ácidos teicóicos, ao passo que as membranas das bactérias G- são compostas por duas camadas de peptidoglicano e lipoproteínas, além de uma camada externa formada por uma membrana caracterizada pela presença de lipopolissacarídeos e proteínas. ${ }^{103,104}$ Por esse motivo, as bactérias G- são mais seletivas à penetração de componentes na célula em comparação às bactérias $\mathrm{G}+$. O tipo de mecanismo de ação antibacteriano da quitosana difere para cada tipo de célula, mas acredita-se que a principal interação das quitosanas seja com as moléculas de peptidoglicano (Figura 6B) e lipopolissacarídeos (Figura 6C). ${ }^{82,101,105-107}$

Machado et al. analisaram filmes à base de quitosana com relação à sua resposta de inibição do crescimento de $E$. coli, uma bactéria G- associada à contaminação e intoxicação alimentar. ${ }^{107}$
Os autores relataram que a atividade bactericida estava relacionada à interação do grupo amino da quitosana com o fosfolipídio dipalmitoil fosfatidilglicerol (DPPG), componente principal das membranas celulares de bactérias G-. Essa interação provoca a saída de componentes intracelulares, como ácidos nucleicos e glicose, e impede o transporte de nutrientes para as células microbianas, causando a morte celular. Resultados semelhantes foram reportados nos trabalhos de Moeini et al. ${ }^{105}$ e Martins et al. ${ }^{106}$

Madureira et al. ${ }^{108}$ descreveram a ação antimicrobiana de nanopartículas de quitosana contra patógenos alimentares $(B$. cereus e $S$. aureus $(\mathrm{G}+)$, E. coli e $S$. typhimurium (G-)). Os autores afirmaram que a quitosana pode agir contra essas bactérias através do rompimento da membrana celular ou pela inibição da replicação de DNA e mRNA. De forma similar, no trabalho de Caroni et al. ${ }^{109}$ os autores estudaram o comportamento de filmes de quitosana e glicerol frente a bactérias G- (E. coli) e G+ (S. aureus e B. cereus). O estudo foi realizado através do método de crescimento bacteriano em placa de petri e análise da formação do halo de inibição. Os resultados mostraram que os filmes tiveram respostas positivas quanto à inibição tanto de bactérias G+ como de bactérias G-.

\section{INFLUÊNCIA DAS CARACTERÍSTICAS ESTRUTURAIS DAS QUITOSANAS NA ATIVIDADE ANTIMICROBIANA}

Conforme mencionado anteriormente, as características estruturais das quitosanas influenciam em suas propriedades funcionais, impactando diretamente sua solubilidade, viscosidade, biodegradabilidade, cristalinidade, biocompatibilidade e bioatividade. ${ }^{24,110}$ Dentre as características físico-químicas do polissacarídeo, o $\overline{G A}$, a $\overline{M M}$, as derivatizações que acarretam hidrossolubilidade e o grau de pureza da amostra interferem de

(A)

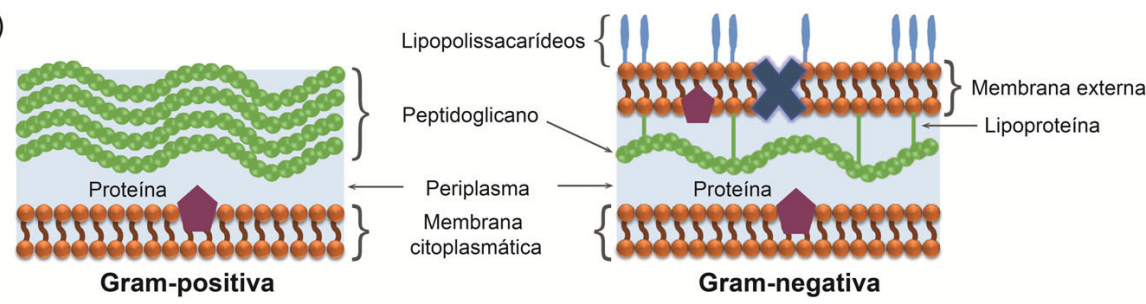

(B)

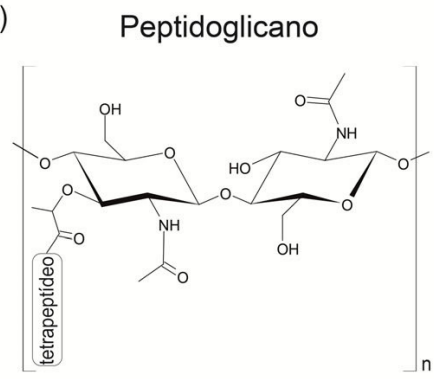

(C)

\section{Lipopolissacarídeos}

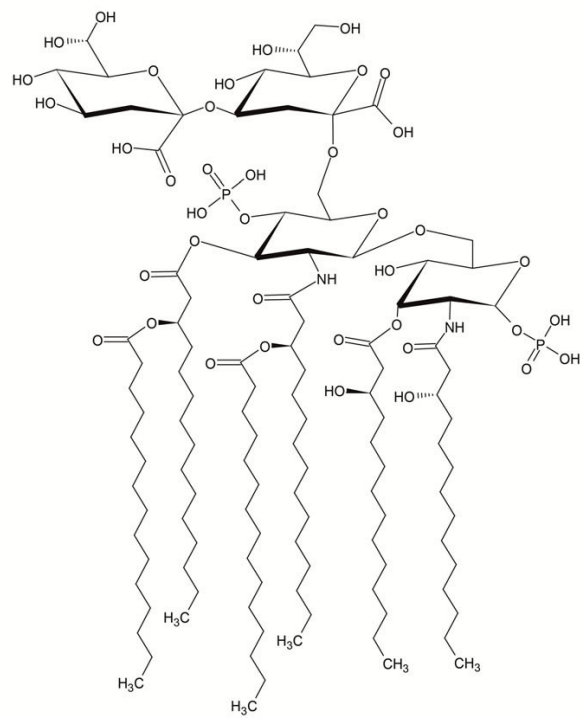

Figura 6. (A) Ilustração esquemática das membranas celulares de bactérias gram-positivas e gram-negativas e estruturas químicas das moléculas de (B) peptidoglicano e (C) lipopolissacarídeos (LPS) 
forma independente em sua atividade antimicrobiana. Além disso, já sabemos que quitosanas com características semelhantes podem ter atividades diferentes a depender dos micro-organismos. Sendo assim, é de extrema importância que essas características sejam previamente definidas a fim de se determinar a composição química/ estrutural mais adequada para a ação antimicrobiana contra cepas específicas. ${ }^{17,19,21,111}$ Conforme já discutido em seções anteriores, essas características podem ser determinadas durante o processo de obtenção de quitina e quitosanas, as quais podem ser moduladas de acordo com as condições reacionais utilizadas. ${ }^{112-114}$

\section{Grau médio de acetilação $(\overline{G A})$}

O grau médio de acetilação $(\overline{G A})$ é uma das características químicas das quitosanas mais importantes que influencia diretamente seu desempenho em muitas aplicações. ${ }^{12,116}$ Esse grau é expresso como uma porcentagem média de grupos de acetilados (GA\%) ou como fração molar de unidades $N$-acetiladas $\left(\mathrm{F}_{\mathrm{A}}\right)$ e determina o teor de grupos $\mathrm{N}$-acetilados. De modo complementar, o grau médio de desacetilação $(\overline{G D})$ indica a porcentagem média de grupos $\mathrm{N}$-desacetilados e, consequentemente, de grupos $-\mathrm{NH}_{2}$ presentes na cadeia polimérica das amostras de quitosana..$^{20,116,117}$ Por ser variável, esse parâmetro interfere nas características físico-químicas do polímero, tais como solubilidade, viscosidade, comportamento polieletrólito, reatividade e estabilidade, afetando diretamente sua aplicabilidade. ${ }^{110,115,118,119}$ Portanto, quitosanas com diferentes $\overline{G A}$ diferem com relação à quantidade média de cargas positivas, podendo ter comportamento variável em suas propriedades biológicas, como, por exemplo, ação antimicrobiana, analgésica, antioxidante, hemostática e mucoadesiva. ${ }^{120,121}$ Além do $\overline{G A}$, o parâmetro de acetilação, que indica como os grupos acetilados estão dispostos na cadeia polimérica da quitosana (podendo ser encontrados distribuídos em bloco, randomicamente ou de maneira alternada), é um fator que influencia suas propriedades físico-químicas e, por consequência, sua atividade antimicrobiana. ${ }^{111}$

Em estudos realizados por Younes et al., em 2014, ${ }^{19}$ quinze amostras de quitosanas com diferentes graus de acetilação e homogeneidade em relação à distribuição dos grupos acetilados nas cadeias foram utilizadas para investigar a eficácia antimicrobiana contra bactérias G- (Escherichia coli, Pseudomonas aeruginosa, Klebsiella pneumoniae e Salmonella typhi), G+ (Staphylococcus aureus, Bacillus cereus, Enterococcus faecalis e Micrococcus luteus) e fungos (Aspergillus niger, Fusarium oxysporum e Alternaria solani). Os autores observaram maior eficiência no efeito inibitório com a diminuição do $\overline{G A}$ e, de modo geral, as amostras apresentaram maior efeito bactericida contra bactérias G-. Em relação à atividade antifúngica, o efeito inibitório testado frente aos fungos $A$. niger e F. oxysporum não apresentou dependência com o $\overline{G A}$ das quitosanas utilizadas. No entanto, para o fungo $A$. solani, os resultados mostraram que seu crescimento foi reduzido com a diminuição do $\overline{G A}$ da quitosana empregada.

Mellegård et al. ${ }^{122}$ utilizaram amostras de quitosana solúveis em água com fração de acetilação $\left(\mathrm{F}_{\mathrm{A}}\right)$ de 0,16 e $0,48(\overline{G A}=16 \%$ e $48 \%$, respectivamente) em testes de inibição do crescimento das bactérias Bacillus cereus, Escherichia coli e Salmonella Typhimurium e três amostras mutantes de LPS de E. coli e S. Typhimurium. Os autores reportaram que quitosanas com $\mathrm{F}_{\mathrm{A}}=0,16$ exerceram maior atividade antibacteriana do que as amostras $\operatorname{com~}_{\mathrm{A}}=0,48$. Ademais, os resultados deste estudo estão de acordo com os obtidos por Younes et al.,${ }^{19}$ uma vez que as diferentes quitosanas empregadas exibiram atividade bactericida maior contra E. coli (G-) do que contra B. cereus $(\mathrm{G}+)$.

Em outro estudo comparativo, Yuan et al. ${ }^{123}$ avaliaram o efeito de quitosanas com quatro valores diferentes de $\overline{G A}$ e verificaram que quanto menor o $\overline{G A}$, maior a atividade antibacteriana contra Escherichia coli e Staphylococcus aureus. A ordem de classificação do $\overline{G A}$ de acordo com a concentração inibitória mínima (CIM) foi $17,9 \%<25,9 \%<24,1 \%<26,5 \%$ para $E$. coli e $17,9 \%<25,9 \% \approx$ $24,1<26,5 \%$ para $S$. Aureus. Como se pode observar, a amostra com $\overline{G D}$ de $82,1 \%$ (menor $\overline{G A}$ ) apresentou maior efeito inibitório para os dois tipos de bactérias. Além disso, foi verificado que a atividade antibacteriana da quitosana foi maior contra Escherichia coli (G-) do que contra Staphylococcus aureus (G+).

Byun et al. ${ }^{124}$ avaliaram o efeito inibitório de quitosanas com $\overline{G A}$ de $18,4 \%$ e $37,3 \%$ no crescimento de diferentes bactérias G- (Salmonella enteritidis e Escherichia coli) e G+ (Listeria monocytogenes e Staphylococcus aureus). Os resultados demonstraram que ambas as amostras inibiram o crescimento dos microrganismos testados, sendo que a quitosana com menor $\overline{G A}(18,4 \%)$ exibiu atividade superior. $\mathrm{O}$ estudo também evidenciou que ambas as quitosanas apresentaram menor atividade antibacteriana contra a bactéria $E$. coli em comparação com as outras três bactérias testadas.

Já os estudos realizados por Jung et al. ${ }^{125}$ compararam as atividades antibacterianas de seis quitosanas solúveis em soluções aquosas ácidas e duas amostras de quitosanas solúveis em água com diferentes $\overline{G A}$ frente a oito bactérias G- (P. fluorescens, P. vulgaris, $E$. carotovora, S. marcescens, E. coli, V. parahaemolyticus, V. vulnificus e $S$. Typhimurium) e seis bactérias $\mathrm{G}+$ (L. monocytogenes, $S$. aureus, $B$. subtilis, B. cereus, L. curvatus e L. plantarum). As atividades antibacterianas das quitosanas solúveis em soluções aquosas ácidas foram superiores às das solúveis em água. Além disso, a atividade diferiu dependendo dos tipos de quitosana e das bactérias testadas. De acordo com o que foi discutido anteriormente, as quitosanas com menor $\overline{G A}$ demonstraram maior atividade antimicrobiana.

A Tabela 1 apresenta os trabalhos científicos que correlacionam a atividade antimicrobiana das quitosanas ao $\overline{G A}$.

\section{Massa molecular média $(\overline{M M})$}

Muitas propriedades físico-químicas e estruturais de uma cadeia polimérica são definidas pela sua massa molecular média $(\overline{M M})$. Uma propriedade bastante influenciada por essa característica é a solubilidade, ${ }^{114,115}$ a qual está diretamente relacionada à atividade antimicrobiana do polímero. ${ }^{114}$ De modo geral, quanto menor a $\overline{M M}$, menor o empacotamento das cadeias e, consequentemente, maior a sua solubilidade. ${ }^{6}$

Conforme discutido nas seções anteriores, é possível obter amostras de quitosanas com $\overrightarrow{M M}$ bastante variável, frequentemente classificadas em alta, média e baixa. Alguns autores ainda utilizam o termo oligoquitosana para definir quitosanas de cadeia curta (geralmente abaixo de $10.000 \mathrm{~g} / \mathrm{mol}$ ). ${ }^{121}$ No entanto, os parâmetros (faixas de $\overline{M M}$ ) que determinam essa classificação são, muitas vezes, encontrados de forma divergente na literatura. ${ }^{23,128,129}$ Diferentes estudos sugerem uma relação entre a $\overline{M M}$ da quitosana e seu mecanismo de ação frente a grupos de micro-organismos específicos. ${ }^{122,123,130}$ Como exemplo, podemos citar os estudos realizados por Younes et al. ${ }^{19}$ os quais mostraram que o uso de quitosanas com diferentes $\overline{M M}$ levou a diferentes efeitos em bactérias $\mathrm{G}+, \mathrm{G}-\mathrm{e}$ fungos. Independente da $\overline{M M}$, os maiores efeitos inibitórios foram observados em bactérias G- em comparação às $\mathrm{G}+$, sendo que em bactérias G- o efeito foi mais pronunciado conforme diminuiu a massa molecular da quitosana utilizada. Já para as bactérias $\mathrm{G}+$, o maior efeito inibitório foi observado na utilização de quitosanas com alta massa molecular. No caso dos fungos, verificou-se que o efeito inibitório depende fortemente do tipo de fungo estudado.

Garcia e colaboradores ${ }^{131}$ mostraram alterações na atividade antifúngica utilizando três quitosanas com $\overline{M M}$ distintas, ou 
Tabela 1. Exemplos de estudos que correlacionam o grau médio de acetilação com a atividade antimicrobiana das quitosanas

\begin{tabular}{|c|c|c|c|}
\hline Amostra & Micro-organismo testado & Principais descobertas & Ref. \\
\hline \multirow{3}{*}{$\begin{array}{l}\text { Quinze amostras de quitosanas com } \\
\qquad \overline{G A} \text { variando de } 2 \% \text { a } 61 \%\end{array}$} & $\begin{array}{l}\text { G- (E. coli, } P \text {. aeruginosa, } \\
\text { K. pneumoniae e } S . \text { typhi) }\end{array}$ & $\begin{array}{l}\text { Para as bactérias: maior eficiência no efeito } \\
\text { inibitório conforme o } \overline{G A} \text { diminui }\end{array}$ & \multirow{3}{*}{19} \\
\hline & $\begin{array}{l}\mathrm{G}+(S . \text { aureus, } B . \text { cereus, } \\
\text { E. faecalis } \text { e } M . \text { luteus })\end{array}$ & $\begin{array}{l}\text { Para os fungos } A \text {. niger e } F \text {. oxysporum: não } \\
\text { houve dependência do efeito inibitório com o } \overline{G A}\end{array}$ & \\
\hline & $\begin{array}{l}\text { Fungos (A. niger, F.oxysporum } \mathrm{e} \\
\text { A. solani) } \\
\end{array}$ & $\begin{array}{l}\text { Para os fungos } A \text {. solani: aumento no efeito } \\
\text { inibitório com a diminuição do } \overline{G A}\end{array}$ & \\
\hline $\begin{array}{l}\text { Quitosanas com } \overline{G A} \text { variando entre } \\
\qquad 16 \% \text { e } 48 \%\end{array}$ & $\begin{array}{c}\text { B. cereus, E. coli, } \\
\text { S. Typhimurium } \\
\text { Três amostras mutantes de LPS de E. coli e } \\
\text { S. Typhimurium. }\end{array}$ & $\begin{array}{l}\text { Quitosanas com menor } \overline{G A} \text { foram mais efetivas } \\
\text { na inibição do que as mais acetiladas }\end{array}$ & 122 \\
\hline $\begin{array}{l}\text { Quitosanas com } \overline{G A} \text { de } 26,5 \% \text {, } \\
25,9 \%, 24,1 \% \text { e } 17,9 \%\end{array}$ & $\begin{array}{c}\mathrm{G}-(\text { E. coli }) \\
\mathrm{G}+(\text { S. aureus })\end{array}$ & $\begin{array}{c}\text { Quanto menor o } \overline{G A} \text {, menor é a concentração } \\
\text { inibitória mínima }\end{array}$ & 123 \\
\hline $\begin{array}{l}\text { Quitosanas com } \overline{G A} \text { de } 16 \%, 14 \% \text {, } \\
\qquad 12 \% \text { e } 6 \%\end{array}$ & Cepas de C. albicans & $\begin{array}{l}\text { Todas as amostras inibiram efetivamente o cresci- } \\
\text { mento de cepas de } C \text {. Albicans. As amostras com } \\
\qquad \overline{G A} \text { menores foram as mais eficazes }\end{array}$ & 126 \\
\hline $\begin{array}{l}\text { Quitosanas com } \overline{G A} \text { de } 37,3 \% \text { e } \\
\qquad 18,4 \%\end{array}$ & $\begin{array}{c}\text { G- (S. Enteritidis e E. coli }) \\
\text { G+ (L. monocytogenes e } S . \text { aureus })\end{array}$ & $\begin{array}{c}\text { A quitosana com } \overline{G A} \text { de } 18,4 \% \text { apresentou ativi- } \\
\text { dade antibacteriana superior }\end{array}$ & 124 \\
\hline $\begin{array}{c}\text { Quitosanas a partir de fungos com } \\
G A \text { de } 14,5 \%, 9,7 \%, 13,7 \% \text { e } 9,8 \% \\
\text { Quitosanas a partir de caranguejo } \\
\text { com } \overline{G A} \text { de } 11,6 \%, 6,7 \%, 12,2 \% \mathrm{e} \\
14,8 \%\end{array}$ & $\begin{array}{c}\mathrm{G}+\text { (B. cereus, L. monocytogenes e } S . \text { aureus }) \\
\mathrm{G}-(\text { E. coli, Flavobacterium } \mathrm{sp} . \\
\text { P. aeruginosa, S. typhimurium } \mathrm{e} \\
\text { V. parahaemolyticus })\end{array}$ & $\begin{array}{c}\text { As amostras a partir de fungos com } \\
\overline{G A}=9,7 \% \text { e } 9,8 \% \text { e de caranguejo com } \\
\overline{G A}=6,7 \% \text { e } 12,2 \% \text { (baixos graus de } \\
N \text { - acetilação) exibiram melhores atividades } \\
\text { antimicrobianas, independentemente de suas } \\
\text { fontes de obtenção }\end{array}$ & 127 \\
\hline $\begin{array}{l}\text { Quitosanas com } \overline{G A} \text { de } 18,4 \% \text { e } \\
\qquad 37,3 \%\end{array}$ & $\begin{array}{c}\text { G- (S. Enteritidis e E. coli) } \\
\text { G+ (L. monocytogenes e S. aureus })\end{array}$ & $\begin{array}{l}\text { Ambas as quitosanas inibiram o crescimento das } \\
\text { cepas, sendo a quitosana com menor } \overline{G A} \text { a que } \\
\text { exibiu atividade superior } \\
\text { A atividade antibacteriana foi menor frente a } \\
\text { E. coli em comparação com os outros tipos de } \\
\text { bactérias }\end{array}$ & 124 \\
\hline $\begin{array}{l}\text { Quitosanas solúveis em solução } \\
\text { ácida com } \overline{G A} \text { variando entre } 0,8 \% \\
\text { e } 10,7 \%\end{array}$ & $\begin{array}{l}\text { G- (P. fluorescens, } P \text {. vulgaris, } \\
\text { E. carotovora, S. marcescens, } \\
\text { E. coli, V. parahaemolyticus, } \\
\text { V. vulnificus e S. Typhimurium })\end{array}$ & $\begin{array}{l}\text { Quitosanas solúveis em soluções aquosas ácidas } \\
\text { apresentaram maior atividade bactericida do que } \\
\text { as solúveis em água }\end{array}$ & 125 \\
\hline $\begin{array}{l}\text { Quitosanas solúveis em água com } \\
\qquad \overline{G A} \text { de } 20 \% \text { e } 36,8 \%\end{array}$ & $\begin{array}{c}\mathrm{G}+(\text { L. monocytogenes, } S . \text { aureus, } \\
\text { B. subtilis, B. cereus, L. curvatus e L. plantarum })\end{array}$ & $\begin{array}{l}\text { Quitosanas com menor } \overline{G A} \text { demonstraram maior } \\
\text { atividade antimicrobiana }\end{array}$ & \\
\hline
\end{tabular}

seja, alta $(248.000 \mathrm{~g} / \mathrm{mol})$, média $(140.000 \mathrm{~g} / \mathrm{mol})$ e baixa $(76.000 \mathrm{~g} / \mathrm{mol})$. Nos testes realizados com fungos do gênero Candida $s s p$, observou-se a redução do crescimento fúngico com o aumento da $\overline{M M}$ da quitosana para as espécies $C$. tropicalis e $C$. parapsilosis. Já para a espécie $C$. albicans, não foi observada nenhuma correlação entre a $\overline{M M}$ e o crescimento fúngico. Em experimentos realizados com fungos da espécie Sporothrix brasiliensis, três quitosanas com $\overline{M M}$ distintas (alta $=984.000,00 \mathrm{~g} / \mathrm{mol}$, média $=467.000,00 \mathrm{~g} / \mathrm{mol}$ e baixa $=206.000,00 \mathrm{~g} / \mathrm{mol}$ ) demonstraram atividade microbiana. Entretanto, a quitosana que apresentou maior efeito inibitório foi aquela com baixa $\overline{M M} \cdot{ }^{132}$ Essas diferenças encontradas na ação antimicrobiana da quitosana para as diferentes espécies podem estar associadas à composição e à densidade de cargas negativas da parede celular do micro-organismo. ${ }^{76,133,134}$

Outros resultados também sugerem relação na redução do crescimento e multiplicação dos micro-organismos de acordo com a $\overline{M M}$ e o micro-organismo testado. ${ }^{19,121}$ Por exemplo, Kaya et al. ${ }^{135}$ compararam a atividade antimicrobiana de quitosanas de baixa e média $\overline{M M}$ frente a nove micro-organismos patogênicos (sete bactérias e duas leveduras). Os estudos revelaram que os efeitos antimicrobianos de ambas as quitosanas diferiram de acordo com os micro-organismos empregados, sendo que os resultados não puderam ser analisados (reunidos) em função dos grupos de bactérias $\mathrm{G}+$ ou
G- e leveduras estudadas. No entanto, os resultados para a bactéria Listeria monocytogenes e para a levedura Candida albicans indicaram que as quitosanas de baixa $\overline{M M}$ apresentaram maior efeito inibitório, ao passo que para a bactéria $B$. subtilis a quitosana de média $\overline{M M}$ foi a que apresentou atividade antimicrobiana mais pronunciada. Dentro da mesma espécie, diferenças significativas foram encontradas entre os valores de inibição para as quitosanas de diferentes $\overline{M M}$ utilizadas.

Bano e colaboradores ${ }^{136}$ conduziram um estudo investigando a atividade bacteriana de quitosanas com $\overline{M M}$ variável contra os patógenos $P$. aeruginosa, E. coli, P. mirabilis e $S$. aureus. Segundo os autores, a quitosana de alta $M M(220.000 \mathrm{~g} / \mathrm{mol})$ não apresentou nenhuma atividade bacteriana, enquanto aquelas de baixa $\overline{M M}$ (801, 473 e $259 \mathrm{~g} / \mathrm{mol}$ ) exibiram atividade contra todas as cepas bacterianas sob investigação. Foi observado que os micro-organismos $P$. aeruginosa e E. coli foram mais sensíveis frente às quitosanas de baixa $\overline{M M}$. Dentre as amostras de baixa $\overline{M M}$ utilizadas, verificouse que quanto menor a $\overline{M M}$ da quitosana, maior o efeito inibitório observado.

Os diferentes comportamentos observados em função da variação da $\overline{M M}$ das quitosanas estão relacionados aos tipos de interação com a célula (ou parede celular), levando a distintos mecanismos de ação. Uma hipótese é a de que quitosanas de alta $\overline{M M}$ apresentam maior dificuldade para penetrar através da membrana celular, 
formando, portanto, películas (barreiras físicas) ao redor da célula que bloqueiam o transporte de nutrientes, resultando em morte celular. ${ }^{76,137,138}$ Quitosanas de alta $\overline{M M}$ podem, ainda, interagir ou ligar-se à membrana celular para modificar sua permeabilidade, causando perturbações na célula e fuga do material intracelular. ${ }^{132}$ Já as quitosanas com cadeias poliméricas de baixa $\overline{M M}$ conseguem penetrar mais facilmente nas células microbianas, inibindo várias enzimas, interrompendo a síntese de proteínas e ligando-se ao DNA; como consequência, elas acabam por inibir a síntese de mRNA, causando distúrbios no metabolismo desses micro-organismos. ${ }^{17,139,140}$

A Tabela 2 apresenta os estudos que correlacionam a atividade antimicrobiana da quitosana com a sua $\overline{M M}$.

Tabela 2. Exemplos de estudos que correlacionam a atividade antimicrobiana da quitosana com sua massa molecular

\begin{tabular}{|c|c|c|c|}
\hline Amostra & Micro-organismo testado & Principais descobertas & Ref. \\
\hline $\begin{array}{l}\text { Quitosanas com alta }(\sim 247.800 \mathrm{~g} / \\
\text { mol }) \text {, média }(\sim 140.500 \mathrm{~g} / \mathrm{mol}) \text { e baixa } \\
(\sim 75.600 \mathrm{~g} / \mathrm{mol}) \text { massas moleculares }\end{array}$ & $\begin{array}{l}\text { C. albicans, } \\
\text { C. tropicalis } \\
\text { C. parapsilosis }\end{array}$ & $\begin{array}{c}\text { Para C. tropicalis e C. parapsilosis, o crescimento fúngico } \\
\text { diminuiu com o aumento da massa molecular da quitosana } \\
\text { Para C. albicans, a massa molecular da quitosana não } \\
\text { modulou o efeito inibitório }\end{array}$ & 131 \\
\hline $\begin{array}{c}\text { Quitosanas com alta } \\
(984.000 \mathrm{~g} / \mathrm{mol}), \\
\text { média }(467.000 \mathrm{~g} / \mathrm{mol}) \text { e baixa } \\
(206.400 \mathrm{~g} / \mathrm{mol}) \text { massas moleculares }\end{array}$ & S. brasiliensis & $\begin{array}{l}\text { Amostras de alta, média e baixa massas moleculares foram } \\
\text { capazes de inibir S. brasiliensis em até } 60 \%, 69 \% \text { e } 88 \% \text {, } \\
\text { respectivamente } \\
\text { Na atividade metabólica, quitosanas de alta, média e baixa } \\
\text { massas moleculares apresentaram valores de inibição de } \\
61 \%, 70 \% \text { e } 89 \% \text {, respectivamente }\end{array}$ & 132 \\
\hline $\begin{array}{c}\text { Oligômero de quitosana } \\
\text { (3.220 g/mol) e quitosana comercial } \\
\text { de média massa molecular (massa } \\
\text { molecular não informada) }\end{array}$ & $\begin{array}{c}\text { Bactérias G+ (L. garvieae, } \\
\text { B. subtilis, S. agalactiae } \mathrm{e} \\
\text { L. monocytogenes) } \\
\text { Bactérias G- (V. alginolyticus, } \\
\text { Y. enterocolitica e S. enteritidis) } \\
\text { Leveduras (C. albicans e } \\
\text { C. glabrata) }\end{array}$ & $\begin{array}{l}\text { Para a bactéria } L \text {. monocytogenes e a levedura } C \text {. albicans, } \\
\text { a quitosana de baixa massa molecular apresentou maior } \\
\text { efeito inibidor } \\
\text { Para a bactéria } B \text {. subtilis, a quitosana de média massa } \\
\text { molecular apresentou maior atividade antimicrobiana }\end{array}$ & 135 \\
\hline
\end{tabular}

C. glabrata) $(220.000 \mathrm{~g} / \mathrm{mol})$ e oligômeros de quito-

Quinze amostras de quitosanas com $\overline{M W}$ variando entre 42.500 e 135.000 $\mathrm{g} / \mathrm{mol}$
Quitosanas de alta massa molecular sana $(801,473$ e $259 \mathrm{~g} / \mathrm{mol})$

\section{P. aeruginosa \\ E. coli \\ P. mirabilis \\ S. aureus}

\section{A amostra com alta massa}

molecular não apresentou atividade bacteriana, enquanto que as de baixa massa molecular exibiram atividade antibacteriana

P. aeruginosa e E. coli foram sensíveis a todos os tipos de quitosana. Quanto menor a massa molecular, maior foi o efeito inibitório
G- (E. coli, P. aeruginosa,

K. pneumoniae e S. typhi)

$\mathrm{G}+($ S. aureus, B. cereus,

E. faecalis e M. luteus)
Para as bactérias G-, a atividade antibacteriana aumentou com a diminuição da $\overline{M W}$, enquanto que o efeito oposto foi observado para as $\mathrm{G}+$

Para os fungos A. niger e A. solani, não houve dependência do efeito inibitório com a $\overline{M W}$

Fungos (A. niger, F. oxysporum e A. solani)

Para os fungos $F$. oxysporum, houve aumento no efeito inibitório com o aumento da $\overline{M W}$

As amostram inibiram efetivamente o crescimento de cepas de $C$. Albicans

As amostras com menor $\overline{M W}$ foram as mais eficazes

$P$. fragi foi a cepa mais resistente ao efeito antimicrobiano, enquanto que $S$. putrefaciens foi a mais sensível

Quitosanas extraídas da casca do camarão com $\overline{M W}$ de $41.000,180.000$ e $400.000 \mathrm{~g} / \mathrm{mol}$

Cepas de C. albicans

S. Putrefaciens

A. hidrófila

Quanto maior a $\overline{M W}$, maior foi o efeito inibitório nas cepas estudadas

Quitosana comercial com $\overline{M W}$ de $194.000 \mathrm{~g} / \mathrm{mol}$; quitooligossacarídeos derivados da quitosana comercial com $\overline{M W}$ de $5.100,14.300$ e $41.100 \mathrm{~g} / \mathrm{mol}$

G- (S. aureus, S. typhimurium e S. enteritidis)

$\mathrm{G}+$ (E. coli)

A quitosana comercial inibiu $S$. aureus mais eficientemente

As bactérias G- foram mais suscetíveis à inibição quanto

Quitosanas com $\overline{M W}$ variando entre 150.000 e $300.000 \mathrm{~g} / \mathrm{mol}$ Bactéria mesofílica Leveduras Bolores menor a $\overline{M W}$

A amostra com menor $\overline{M W}$ apresentou melhor efeito microbiológico

Quitosanas com $\overline{M W}$ de 3.300, 7.100,

$29.200,72.100,156.000$ e $300.000 \mathrm{~g} /$ mol

E. coli

E. aureus aumento da $\overline{M W}$

Em pH neutro, a atividade aumentou à medida que a $\overline{M W}$ diminuiu 


\section{Derivados hidrossolúveis}

Uma importante vantagem de se trabalhar com quitosanas é a possibilidade de se preparar uma grande variedade de derivados. Nos últimos anos, diferentes estratégias de derivatização vêm sendo predominantemente realizadas com o objetivo de melhorar certas propriedades das quitosanas. ${ }^{145-147} \mathrm{O} \mathrm{pH}$ levemente ácido geralmente necessário para solubilização de quitosanas $\left(\mathrm{pK}_{\mathrm{a}} \sim 6,3\right)$, por exemplo, pode resultar em limitações para certas aplicações. ${ }^{44,148} \mathrm{~A}$ solubilidade dependente do $\mathrm{pH}$ é atribuída à presença dos grupamentos amina, os quais se tornam protonados após dissolução em $\mathrm{pH}<6 .{ }^{75}$ Para aumentar a solubilidade e possibilitar a utilização das quitosanas em uma faixa mais ampla de $\mathrm{pH}$, vários derivados hidrossolúveis vêm sendo desenvolvidos. ${ }^{149}$ Vale ressaltar que modificações químicas nas quitosanas podem ser dificultadas em razão de sua cristalinidade e da presença de ligações de hidrogênio intra e intermoleculares em suas cadeias. ${ }^{150}$ No entanto, com o passar dos anos, diferentes grupos de pesquisa vêm relatando a obtenção de derivados hidrossolúveis através da modificação química, realizada principalmente nos três grupamentos funcionais nucleofílicos: amina no carbono C2 (C2$\left.\mathrm{NH}_{2}\right)$, hidroxila secundária no carbono $\mathrm{C} 3(\mathrm{C} 3-\mathrm{OH})$ e hidroxila primária no carbono $\mathrm{C} 6(\mathrm{C} 6-\mathrm{OH}),{ }^{102,151}$ conforme ilustrado na Figura 7A. Esses grupamentos podem ser prontamente submetidos à derivatização química em condições reacionais brandas, permitindo a modulação das propriedades antimicrobianas da quitosana. ${ }^{22,148}$ $\mathrm{O}$ maior impedimento estérico associado à hidroxila secundária no carbono $\mathrm{C} 3$ faz com que a formação de derivados através da substituição nessa posição seja dificultada, e poucos são os relatos de derivados sintetizados seguindo essa estratégia. ${ }^{145}$ Os grupos funcionais mais comumente presentes em derivados antimicrobianos de quitosana são: amônio quaternário, fosfônio, guanidinil, carboxialquil, hidroxialquil e grupos contendo tiol. ${ }^{22}$ É importante destacar que as rotas de síntese convencionais empregadas geralmente resultam em produtos que podem ser substituídos em todos os três centros reativos das quitosanas, o que leva à formação de um produto sem especificidade no grupo substituído ou com um baixo grau de substituição. Para que esses problemas sejam superados, diferentes tipos de grupos protetores são empregados a fim de se bloquear o grupo $\mathrm{C} 2-\mathrm{NH}_{2}$ ou os grupos $\mathrm{C} 3-\mathrm{OH}$ e C6-OH. ${ }^{44,152}$

Levando em consideração os mecanismos de ação das quitosanas discutidos anteriormente, é razoável pensar que uma das estratégias para aumentar sua atividade antimicrobiana seja a preparação de derivados hidrossolúveis através da introdução de cargas positivas nas cadeias poliméricas. ${ }^{20}$ Por esse motivo, grande parte dos trabalhos que avaliam a influência do processo de derivatização nas propriedades antimicrobiana das quitosanas reportam a síntese de derivados catiônicos. ${ }^{22,23,152,154}$ Nesse sentido, diversos estudos reportam a introdução de substituintes ao grupamento amina no C2 para a formação de sais de amônio quaternário e derivados de quitosanas solúveis em uma faixa de $\mathrm{pH}$ maior (incluindo o $\mathrm{pH}$ neutro) e com maior ação antimicrobiana em comparação às quitosanas não modificadas. ${ }^{44,155}$ Um estudo comparativo conduzido por Rúnarsson et al. revelou que apenas o derivado quaternário $N, N, N$-trimetil quitosana (TMQ), carregado positivamente, apresentou atividade contra a bactéria $S$. aureus, enquanto que os derivados neutros mono- e dimetilados e a quitosana não substituída não apresentaram
(A)

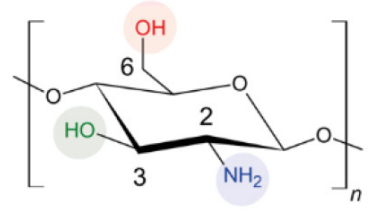

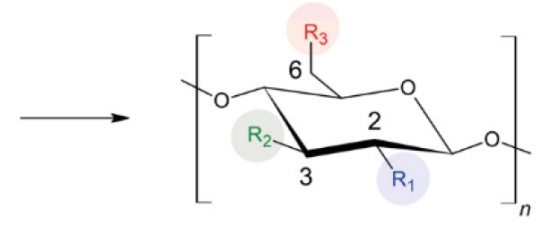

(B)

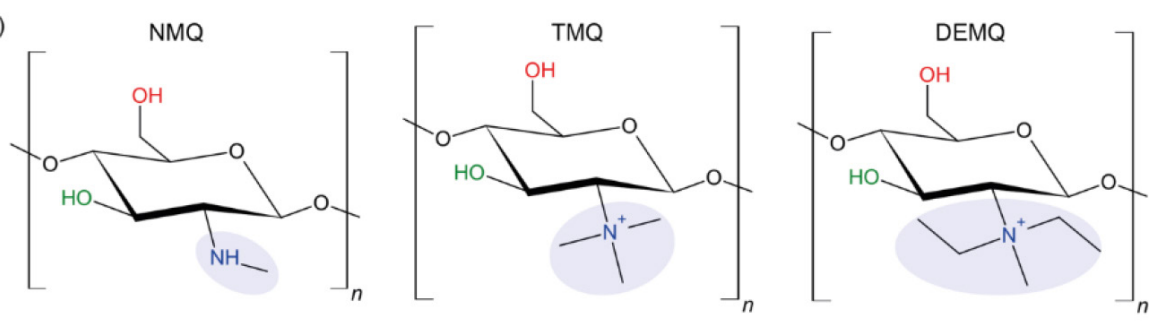

(C)

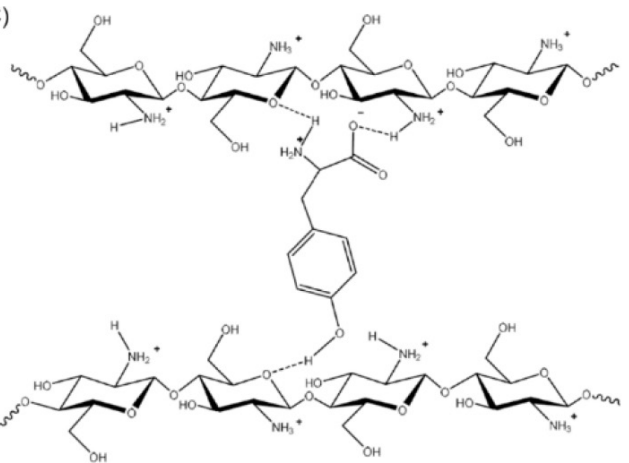

(D)

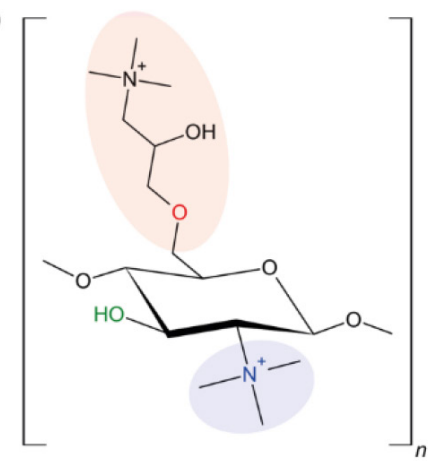

Figura 7. (A) Esquema sintético ilustrando os grupos funcionais da estrutura química das quitosanas que possibilitam a obtenção de derivados hidrossolúveis. (B) Estruturas químicas dos derivados NMQ, TMQ e DEMQ. (C) Representação esquemática da formação do conjugado quitosana-tirosina através de ligações de hidrogênio. Reproduzido da ref. 154. Copyright 2020 MDPI sob uma licença Creative Commons 4.0 (CC BY) (http://creativecommons.org/licenses/by/4.0/). (D) Estrutura química do derivado N,N,N-trimetil-O-(2-hidroxi-3-trimetilamônio propil) 
atividade antimicrobiana em $\mathrm{pH}=7,2 .{ }^{156} \mathrm{Em}$ outro trabalho, Bakshi e colaboradores avaliaram a atividade antimicrobiana de diferentes derivados $N$-alquilados frente às bactérias $E$. coli e $S$. aureus. ${ }^{157}$ Por meio da substituição eletrofílica no grupamento $\mathrm{C} 2-\mathrm{NH}_{2}$, três derivados foram sintetizados: $N$-metil quitosana (NMQ), TMQ e $N, N$ dietil- $N$-metil quitosana (DEMQ), conforme ilustrado na Figura 7B. Observou-se que a atividade antimicrobiana seguiu a ordem: DEMQ $<$ quitosana $<$ NMQ < TMQ. O derivado quaternário TMQ induziu a maior resposta antibactericida em virtude da presença das cargas positivas permanentes na estrutura das quitosanas. Apesar de também apresentar carga, o derivado DEMQ não apresentou a atividade antimicrobiana esperada, possivelmente devido ao impedimento estérico do substituinte mais volumoso. A presença de cargas positivas na estrutura das quitosanas é acompanhada da presença de um contra-íon. A fim de se avaliar a influência do contra-íon na atividade bactericida frente a $S$. aureus e E.coli, Follmann et al. sintetizaram o derivado TMQ contendo os seguintes contra-íons: sulfato, acetato, cloreto, brometo e iodeto. ${ }^{158}$ A maior atividade foi observada para os derivados contendo os íons acetato e sulfato, possivelmente devido à maior deslocalização eletrônica.

Estudos recentes têm reportado a obtenção de derivados hidrossolúveis a partir do acoplamento de quitosanas com peptídeos/ aminoácidos..$^{22,152,153}$ Seguindo essa abordagem, Buzón-Durán e colaboradores demonstraram que a associação via ligações de hidrogênio dos aminoácidos glicina, prolina e tirosina à quitosana resultou em uma melhor atividade antifúngica contra Fusarium culmorum, um fungo patógeno responsável por várias doenças em cereais. ${ }^{153}$ Testes in vitro mostraram um aumento da inibição do crescimento micelial, com valores de concentração efetiva que induz $50 \%\left(\mathrm{EC}_{50}\right)$ e $90 \%\left(\mathrm{EC}_{90}\right)$ do efeito máximo variando de 320 a $948 \mu \mathrm{g} \mathrm{mL}^{-1}$ e de 1107 a $1407 \mu \mathrm{g} \mathrm{mL}^{-1}$, respectivamente valores esses bem inferiores aos apresentados pela quitosana e pelos aminoácidos isolados. A melhor resposta foi obtida pelo conjugado quitosana-tirosina (Figura 7C), o que os autores atribuíram à redução da cristalinidade da quitosana em função ao rearranjo das cadeias poliméricas e ao aumento de carga catiônica superficial com a formação do conjugado. Ensaios com plantas e experimentos de campo em pequena escala mostraram que a melhor formulação não apresentou efeitos fitotóxicos e reduziu significativamente a severidade do desenvolvimento dos sintomas do fungo. A síntese de derivados de quitosanas-guanidinilados também desperta grande interesse, fazendo com que eles sejam investigados como materiais antimicrobianos em virtude de sua alta solubilidade em água, rápida resposta e baixa toxicidade. ${ }^{22,102,148,152,159}$ A guanidina, considerada uma das bases orgânicas mais fortes, confere às quitosanas um grande caráter catiônico em $\mathrm{pH}$ fisiológico, permitindo a formação de fortes interações não covalentes com alguns componentes carregados negativamente, como, por exemplo, grupos fosfatos da superfície celular da célula microbiana. ${ }^{152}$

Derivados catiônicos também podem ser obtidos através de reações de substituição nas hidroxilas. Rahimi e colaboradores relataram a síntese de derivados de quitosanas através da inserção de um grupo imidazol carregado ao C6-OH. ${ }^{160}$ As atividades antibacteriana e antifúngica do derivado frente às bactérias E. coli, S. aureus, Pseudomonas aeruginosa, Candida albicans e Pseudomonas aeruginosa (cepa de bactéria resistente a drogas) foram superiores às da quitosana, sendo que o melhor desempenho foi atribuído aos grupos imidazóis protonados. Recentemente, Li et al. reportaram a síntese do cloreto de 2'-O-hidroxipropiltrimetilamônio quitosana e avaliaram sua atividade frente às bactérias $E$. coli e S. aureus. ${ }^{161} \mathrm{O}$ elevado efeito antibacteriano do derivado, quando comparado aos materiais de partida, foi atribuído à presença dos grupamentos $\mathrm{C} 2-\mathrm{NH}_{2}$ e do substituinte $-\mathrm{N}^{+}\left(\mathrm{CH}_{3}\right)_{3}$.
Diversos estudos também relatam a influência de mais de um substituinte na cadeia polimérica. Por exemplo, o grupo amino no $\mathrm{C} 2$ e o grupo hidroxila primário no $\mathrm{C} 6$ das quitosanas podem ser modificados, ao mesmo tempo em que levam à obtenção de derivados hidrossolúveis com alta atividade antimicrobiana. ${ }^{151} \mathrm{Xu}$ et al. demonstraram que o derivado $\mathrm{N}, \mathrm{N}, \mathrm{N}$-trimetil-O-(2-hidroxi3 -trimetilamônio propil) (Figura 7D) quitosana apresentou atividade antibacteriana aumentada em comparação com o derivado $N, N, N$-trimetil quitosana e quitosana. ${ }^{162} \mathrm{O}$ maior grau de substituição no derivado $\mathrm{N}, \mathrm{O}$-carboximetilquitosana também resultou em maior atividade antibacteriana contra $S$. aureus do que a ação do derivado $O$-carboximetilquitosana e da quitosana. ${ }^{151} \mathrm{Li}$ e colaboradores avaliaram a influência da inserção do grupo funcional acil tioureia ao grupamento $\mathrm{C} 2-\mathrm{NH}_{2}$ em um derivado $O$-substituído da quitosana ( $O$-quaternário de amônio). ${ }^{134} \mathrm{~A}$ introdução dos grupos acil tioureia aumentaram a eletropositividade do derivado dissubstituído, acarretando maior supressão ao crescimento de bactérias G+ e G- em comparação ao derivado $O$-substituído e à quitosana. ${ }^{134} \mathrm{Em}$ outro estudo, Fan et al. relataram a obtenção de derivados hidrossolúveis através da inserção de grupos poliaminoetil e dietoxiforforil aos grupamentos $\mathrm{C} 6-\mathrm{OH}$ e C2- $\mathrm{NH}_{2}$, respectivamente, para aumentar a atividade antifúngica da quitosana frente aos fungos Botrytis cinerea, Phytophthora capsici e Fusarium solani. ${ }^{152}$

O grau médio de substituição $(\overline{G S})$ ou a proporção dos grupos funcionais inseridos à estrutura das quitosanas também tem efeito nas propriedades antimicrobianas da quitosana frente a várias cepas de bactérias e fungos. Sahariah e Másson publicaram um artigo de revisão fazendo uma comparação entre diferentes derivados de quitosanas hidrossolúveis e demostraram que para derivados catiônicos a eficácia antibacteriana geralmente aumenta com o aumento da proporção dos grupos funcionais ligados à cadeia polimérica. ${ }^{22}$

\section{INFLUÊNCIA DO GRAU DE PUREZA DA AMOSTRA NA ATIVIDADE BIOLÓGICA}

Além das características estruturais discutidas anteriormente, as propriedades das quitosanas também são afetadas pelo seu grau de pureza. ${ }^{162}$ De fato, no contexto de aplicações biomédicas, por exemplo, requer-se um grau de pureza elevado. Estudos relatam que a pureza das quitosanas influencia seu perfil toxicológico. ${ }^{163} \mathrm{As}$ diferenças na pureza do polissacarídeo podem estar relacionadas às condições de tratamento químico durante a obtenção da quitina e à transformação da quitina em quitosanas, incluindo a sequência de desmineralização, desproteinização, despigmentação e desacetilação, a concentração dos produtos químicos empregados e o tempo de reação. ${ }^{150,164}$ Sendo assim, a etapa de purificação das quitosanas se dá por meio de processos químicos visando a remoção de minerais, proteínas e pigmentos. Ardila e colaboradores reportaram que a presença de proteínas residuais pode levar a uma diminuição da propriedade antibactericida da quitosana. ${ }^{164}$ Segundo os autores, essas impurezas podem representar uma fonte de nutrientes para as bactérias e, portanto, serem responsáveis pela diminuição da atividade antimicrobiana acima de uma concentração crítica. Após a etapa de desproteinização utilizando a enzima proteinase K, uma concentração mais baixa de quitosana foi suficiente para erradicar as bactérias $E$. coli, L. innocua e S. aureus.

Outro tipo de contaminação frequente em amostras de quitosanas, especialmente as que possuem como fonte de matéria-prima organismos marinhos, é a contaminação por metais pesados. ${ }^{111,165}$ Contaminações por cadmio e arsênio são as mais tipicamente testadas por serem esses os metais mais citotóxicos. Entretanto, outros metais como crômio, níquel, cobre e zinco também podem ser detectados em amostras comerciais. Além de serem provenientes da 
fonte de matéria-prima, esses contaminantes podem ser associados às quitosanas nas etapas de produção das amostras devido à sua capacidade de complexação com metais pesados. Diferentes autores reportam que a presença de resíduos de metais pesados pode acarretar uma acentuada redução da atividade bactericida das quitosanas. ${ }^{165}$ No entanto, é importante destacar que também existem trabalhos na literatura que demonstram uma melhora da propriedade antimicrobiana após a incorporação de íons metálicos, tais como $\mathrm{Ag}^{+}$, $\mathrm{Cu}^{2+}, \mathrm{Zn}^{2+} \mathrm{Mnn}^{2+}$, às quitosanas. ${ }^{166}$

Apesar da importância desse parâmetro, principalmente no cenário de aplicações biomédicas, poucos são os trabalhos na literatura que avaliam a influência da pureza na atividade antimicrobiana das quitosanas. O grande interesse pelo uso de quitosanas e seus derivados faz com que seja importante padronizar os aspectos relacionados a esses compostos, uma vez que isso permitirá eliminar a ambiguidade persistente sobre seu grau de pureza e demais características estruturais, incluindo o grau de acetilação/desacetilação, a massa molecular e outras importantes propriedades encontradas na literatura científica para este biopolímero.

\section{CONSIDERAÇÕES FINAIS E PERSPECTIVAS}

Quitosanas são polímeros versáteis, de vasta aplicação e com comprovada atividade antimicrobiana. $O$ processo de obtenção desse polissacarídeo pode ser realizado através de reações de desacetilação da quitina, em que processos físico-químicos ou mediados por enzimas e micro-organismos são utilizados, ou através da extração direta da natureza, utilizando-se processos biotecnológicos. Ambos os processos de obtenção devem ter suas etapas muito controladas, pois têm influência direta nas caraterísticas estruturais das quitosanas e, consequentemente, em suas propriedades, como, por exemplo, sua atividade antimicrobiana. Algumas hipóteses são citadas na literatura sobre a ação de quitosanas frente a micro-organismos, dentre elas a alteração da permeabilidade da membrana celular do micro-organismo que impede as trocas gasosas entre o interior e o exterior da célula. Tal alteração leva à ruptura da membrana celular de bactérias ou da parede celular fúngica, à inibição da síntese de mRNA e proteínas e/ou à formação de barreira externa, consequentemente impedindo a entrada de nutrientes e o crescimento microbiano. De fato, todas as hipóteses de ação das quitosanas estão principalmente relacionadas com a interação entre as cargas positivas dos grupos amino protonados das quitosanas e as cargas negativas presentes na membrana/parede celular de bactérias e fungos. Sendo assim, tanto o $\overline{G A}$ como a $\overline{M M}$ do polímero são características importantes na determinação de sua ação. De maneira geral, quanto menor o $\overline{G A}$, maior é a atividade das quitosanas frente aos micro-organismos. Já com relação à $\overline{M M}$, a atividade das quitosanas depende muito mais da espécie do micro-organismo (sua composição/estrutura), sendo que cadeias poliméricas maiores parecem inibir as células através do envolvimento das mesmas, enquanto cadeias poliméricas menores podem penetrar o interior das células. Derivados hidrossolúveis de quitosanas são geralmente sintetizados através da inserção de grupos que desenvolvem carga positiva em sua cadeia polimérica, favorecendo a ação antimicrobiana em ampla faixa de pH. Em relação à pureza das quitosanas, poucos trabalhos na literatura citam essa importante característica em relação à atividade bactericida, porém, alguns trabalhos mostram que sua associação com resíduos proteicos diminui sua atividade. É importante destacar que apesar de importantes informações poderem ser obtidas através da compilação dos dados presentes na literatura acerca da estrutura/atividade de quitosanas frente a micro-organismos, ainda há muito que se estudar sobre o tópico devido ao grande número de parâmetros que possam influenciar e estar envolvidos no processo. Além disso, a obtenção de quitosanas com características estruturais controladas e através de processos que apresentem produto reprodutível configura adicional dificuldade. Por fim, ainda existem vários desafios que precisam ser enfrentados a fim de delinear o mecanismo de ação da quitosana visando aplicações práticas, como, por exemplo, a preparação de nanoestruturas utilizadas no desenvolvimento de produtos com atividade antimicrobiana que possam ser futuramente utilizadas em escala industrial.

\section{AGRADECIMENTOS}

Os autores agradecem o apoio financeiro da Fundação de Amparo à Pesquisa do Estado de São Paulo - FAPESP (Processos nº 17/194708 e 17/20973-4), do Conselho Nacional de Desenvolvimento Científico e Tecnológico - CNPq, da Coordenação de Aperfeiçoamento de Pessoal de Nível Superior - CAPES e da Fundação de Amparo à Pesquisa do Estado de Minas Gerais - FAPEMIG (Processo $\mathrm{n}^{\circ}$ APQ-00373-18).

\section{REFERÊNCIAS}

1. Synowiecki, J.; Al-khateeb, N. A.; Synowiecki, J.; Crit. Rev. Food Sci. Nutr. 2010, 43, 145.

2. Dash, M.; Chiellini, F.; Ottenbrite, R. M.; Chiellini, E.; Prog. Polym. Sci. 2011, 36, 981.

3. Kaur, S.; Dhillon, G. S.; Crit. Rev. Microbiol. 2014, 40, 155.

4. El Knidri, H.; Belaabed, R.; Addaou, A.; Laajeb, A.; Lahsini, A.; Int. J. Biol. Macromol. 2018, 120, 1181.

5. Pillai, C. K. S.; Paul, W.; Sharma, C. P.; Prog. Polym. Sci. 2009, 34, 641.

6. Zargar, V.; Asghari, M.; Dashti, A.; ChemBioEng Rev. 2015, $2,204$.

7. Kumar, M. N. V. R.; React. Funct. Polym. 2000, 46, 1.

8. De Britto, D.; Pinola, F. G.; Mattoso, L. H. C.; Assis, O. B. G.; Quim. Nova 2016, 39, 1126

9. Lins, L. C.; Bazzo, G. C.; Barreto, P. L. M.; Pires, A. T. N.; J. Braz. Chem. Soc. 2014, 25, 1462.

10. Ungureanu, C.; Ioniţă, D.; Berteanu, E.; Tcacenco, L.; Zuav, A.; Demetrescu, I.; J. Braz. Chem. Soc. 2015, 26, 458.

11. Aranaz, I.; Acosta, N.; Civera, C.; Elorza, B.; Mingo, J.; Castro, C.; Gandía, M. de los L.; Caballero, A. H.; Polymers (Basel). 2018, 10.

12. Rinaudo, M.; Prog. Polym. Sci. 2006, 31, 603.

13. Muxika, A.; Etxabide, A.; Uranga, J.; Guerrero, P.; de la Caba, K.; Int. J. Biol. Macromol. 2017, 105, 1358.

14. Campana-Filho, S. P.; De Britto, D.; Curti, E.; Abreu, F. R.; Cardoso, M. B.; Battisti, M. V.; Sim, P. C.; Goy, R. C.; Signini, R.; Lavall, R. L.; Quim. Nova 2007, 30, 644.

15. Younes, I.; Rinaudo, M.; Mar. Drugs 2015, 13, 1133.

16. Messa, L. L.; Froes, J. D.; Souza, C. F.; Faez, R.; Quim. Nova 2016, 39, 1215.

17. Kong, M.; Chen, X. G.; Xing, K.; Park, H. J.; Int. J. Food Microbiol. 2010, 144, 51

18. Rabea, E. I.; Badawy, M. E.-T.; Stevens, C. V; Smagghe, G.; Steurbaut, W.; Biomacromolecules 2003, 4, 1457.

19. Younes, I.; Sellimi, S.; Rinaudo, M.; Jellouli, K.; Nasri, M.; Int. J. Food Microbiol. 2014, 185, 57.

20. Hosseinnejad, M.; Jafari, S. M.; Int. J. Biol. Macromol. 2016, 85, 467.

21. Lizardi-Mendoza, J.; Argüelles Monal, W. M.; Goycoolea Valencia, F. M.; Chemical Characteristics and Functional Properties of Chitosan; Elsevier Inc.: Amsterdam, 2016.

22. Sahariah, P.; Másson, M.; Biomacromolecules 2017, acs. biomac.7b01058.

23. Goy, R. C.; De Britto, D.; Assis, O. B. G.; Polimeros 2009, 19, 241.

24. Marques, C.; Som, C.; Schmutz, M.; Borges, O.; Borchard, G.; Front. Bioeng. Biotechnol. 2020, 8, 165. 
25. Kou, S. (Gabriel); Peters, L. M.; Mucalo, M. R.; Int. J. Biol. Macromol. 2021, 169, 85 .

26. Mohan, K.; Ganesan, A. R.; Muralisankar, T.; Jayakumar, R.; Sathishkumar, P.; Uthayakumar, V.; Chandirasekar, R.; Revathi, N.; Trends Food Sci. Technol. 2020, 105, 17.

27. Fiamingo, A.; Delezuk, J. A. D. M.; Trombotto, S.; David, L.; CampanaFilho, S. P.; Ultrason. Sonochem. 2016, 32, 79.

28. Lavall, R. L.; Assis, O. B. G.; Campana-Filho, S. P.; Bioresour. Technol. 2007, 98, 2465.

29. Joseph, S. M.; Krishnamoorthy, S.; Paranthaman, R.; Moses, J. A.; Anandharamakrishnan, C.; Carbohydr. Polym. Technol. Appl. 2021, 2, 100036.

30. Said Al Hoqani, H. A.; AL-Shaqsi, N.; Hossain, M. A.; Al Sibani, M. A.; Carbohydr. Res. 2020, 492, 108001.

31. Percot, A.; Viton, C.; Domard, A.; Biomacromolecules 2003, 4, 12.

32. Al Shaqsi, N. H. K.; Al Hoqani, H. A. S.; Hossain, M. A.; Al Sibani, M. A.; Biochem. Biophys. Reports 2020, 23, 100779.

33. Roberts, G. A. F.; Roberts, G. A. F.; Chitin Chemistry; Macmillan Education: UK, 1992; pp. 54.

34. Hu, J.; Lu, W.; Lv, M.; Wang, Y.; Ding, R.; Wang, L.; Rev. Bras. Farmacogn. 2019, 29, 24.

35. Dave, D.; Liu, Y.; Pohling, J.; Trenholm, S.; Murphy, W.; Bioresour. Technol. Reports 2020, 11, 100535.

36. Hahn, T.; Tafi, E.; Paul, A.; Salvia, R.; Falabella, P.; Zibek, S.; J. Chem. Technol. Biotechnol. 2020, 95, 2775.

37. Nguyen, T. T.; Barber, A. R.; Smith, P.; Luo, X.; Zhang, W.; Food Bioprod. Process. 2017, 102, 367.

38. Khayrova, A.; Lopatin, S.; Varlamov, V.; Int. J. Biol. Macromol. 2021, 167, 1319.

39. Deng, J. J.; Mao, H. H.; Fang, W.; Li, Z. Q.; Shi, D.; Li, Z. W.; Zhou, T.; Luo, X. C.; J. Clean. Prod. 2020, 271, 122655.

40. Delezuk, J. A. de M.; Pavinatto, A.; Campana-Filho, S. P.; Mater. Today Proc. 2019, 14, 722.

41. Delezuk, J. A. de M.; Cardoso, M. B.; Domard, A.; Campana-Filho, S. P.; Polym. Int. 2011, 60, 903.

42. Tan, T. S.; Chin, H. Y.; Tsai, M. L.; Liu, C. L.; Carbohydr. Polym. 2015, $122,321$.

43. Yaghobi, N.; Hormozi, F.; Carbohydr. Polym. 2010, 81, 892.

44. Abd El-Hack, M. E.; El-Saadony, M. T.; Shafi, M. E.; Zabermawi, N. M.; Arif, M.; Batiha, G. E.; Khafaga, A. F.; Abd El-Hakim, Y. M.; AlSagheer, A. A.; Int. J. Biol. Macromol. 2020, 164, 2726.

45. Manni, L.; Ghorbel-Bellaaj, O.; Jellouli, K.; Younes, I.; Nasri, M.; Appl. Biochem. Biotechnol. 2010, 162, 345

46. Kaur, S.; Dhillon, G. S.; Crit. Rev. Biotechnol. 2015, 35, 44.

47. Synowiecki, J.; Al-Khateeb, N. A. A. Q.; Food Chem. 2000, 68, 147

48. Mao, X.; Guo, N.; Sun, J.; Xue, C.; J. Clean. Prod. 2017, 143, 814.

49. Hembach, L.; Cord-Landwehr, S.; Moerschbacher, B. M.; Sci. Rep. 2017, 7, 1 .

50. Duong, N. T. H.; Nghia, N. D.; J. Chitin Chitosan Sci. 2014, $2,21$.

51. Valdez-Peña, A. U.; Espinoza-Perez, J. D.; Sandoval-Fabian, G. C.; Balagurusamy, N.; Hernandez-Rivera, A.; de-la-Garza-Rodriguez, I. M.; Contreras-Esquivel, J. C.; Sci. Biotechnol. 2010, 19, 553.

52. Haddar, A.; Hmidet, N.; Ghorbel-Bellaaj, O.; Fakhfakh-Zouari, N.; Sellami-Kamoun, A.; Nasri, M.; Biotechnol. Bioprocess Eng. 2011, 16, 669.

53. Sila, A.; Nasri, R.; Bougatef, A.; Nasri, M.; J. Aquat. Food Prod. Technol. 2012, 21, 118 .

54. Casadidio, C.; Peregrina, D. V.; Gigliobianco, M. R.; Deng, S.; Censi, R.; Di Martino, P.; Mar. Drugs 2019, 17.

55. Shirai, K.; Guerrero, I.; Huerta, S.; Saucedo, G.; Castillo, A.; Obdulia Gonzalez, R.; Hall, G. M.; Enzyme Microb. Technol. 2001, 28, 446.

56. Gortari, M. C.; Hours, R. A.; Electron. J. Biotechnol. 2013, 16.

57. Arbia, W.; Arbia, L.; Adour, L.; Amrane, A.; Chitin Recover. Using Biol. Methods, Food Technol. Biotechnol. 2013, 51, 12.
58. Cremades, O.; Ponce, E.; Corpas, R.; Gutiérrez, J. F.; Jover, M.; AlvarezOssorio, M. C.; Parrado, J.; Bautista, J.; J. Agric. Food Chem. 2001, 49, 5468.

59. Bautista, J.; Jover, M.; Gutierrez, J. F.; Corpas, R.; Cremades, O.; Fontiveros, E.; Iglesias, F.; Vega, J.; Process Biochem. 2001, 37, 229.

60. Hoover, D. G.; Food Biotechnol. 1993, 7, 11.

61. Muslim, S. N.; AL-Kadmy, I. M.; Ali, A. N. M.; Dwaish, A. S.; Khazaal, S. S.; Muslim, S. N.; Aziz, S. N.; Adv. Biotechnol. 2018, 1.

62. Ghormade, V.; Pathan, E. K.; Deshpande, M. V.; Int. J. Biol. Macromol. 2017, 104, 1415.

63. de Souza, A. F.; Galindo, H. M.; de Lima, M. A. B.; Ribeaux, D. R.; Rodríguez, D. M.; Andrade, R. F. da S.; Gusmão, N. B.; de CamposTakaki, G. M.; Int. J. Mol. Sci. 2020, 21, 1.

64. Sebastian, J.; Rouissi, T.; Brar, S. K.; In Handbook of Chitin and Chitosan v.1; Gopi, S., Thomas, S., Pius, A.; eds, Elsevier: Amsterdam 2020.

65. Berger, L. R. R.; Stamford, T. C. M.; Stamford-Arnaud, T. M.; De Oliveira Franco, L.; Do Nascimento, A. E.; Horacinna, H. M.; Macedo, R. O.; De Campos-Takaki, G. M.; Molecules 2014, 19, 2771.

66. Martinou, A.; Kafetzopoulos, D.; Bouriotis, V.; Carbohydr. Res. 1995, $273,235$.

67. Alfonso, C.; Nuero, O. M.; Santamaría, F.; Reyes, F.; Curr. Microbiol. 1995, 30, 49.

68. Tsigos, I.; Martinou, A.; Kafetzopoulos, D.; Bouriotis, V.; TibTech 2000, $18,129$.

69. Kaczmarek, M. B.; Struszczyk-Swita, K.; Li, X.; Szczęsna-Antczak, M.; Daroch, M.; Front. Bioeng. Biotechnol. 2019, 7.

70. Smets, G.; Rüdelsheim, P.; N. Biotechnol. 2018, 42, 42.

71. Sahariah, P.; Hjálmarsdóttir, M. Á.; Másson, M. In Marine Glycobiology; Kim, S.-K., ed; CRC Press: Boca Raton, 2016; pp. 345.

72. Wei, L.; Tan, W.; Wang, G.; Li, Q.; Dong, F.; Guo, Z.; Carbohydr. Polym. 2019, 226, 115256.

73. Qin, Y.; Li, P.; Int. J. Mol. Sci. 2020, 21, 499.

74. Pavinatto, A.; de Almeida Mattos, A. V.; Malpass, A. C. G.; Okura, M. H.; Balogh, D. T.; Sanfelice, R. C.; Int. J. Biol. Macromol. 2020, 151, 1004.

75. Raafat, D.; Sahl, H. G.; Microb. Biotechnol. 2009, 2, 186.

76. Li, X. fang; Feng, X. qiang; Yang, S.; Fu, G. qing; Wang, T. pu; Su, Z. xing; Carbohydr. Polym. 2010, 79, 493.

77. Xing, K.; Chen, X. G.; Liu, C. S.; Cha, D. S.; Park, H. J.; Int. J. Food Microbiol. 2009, 132, 127.

78. Lee, D. S.; Je, J. Y.; J. Agric. Food Chem. 2013, 61, 6574.

79. Park, S. C.; Nah, J. W.; Park, Y.; Macromol. Res. 2011, 19, 853.

80. Galván Márquez, I.; Akuaku, J.; Cruz, I.; Cheetham, J.; Golshani, A.; Smith, M. L.; Int. J. Food Microbiol. 2013, 164, 108.

81. Mansilla, A. Y.; Albertengo, L.; Rodríguez, M. S.; Debbaudt, A.; Zúñiga, A.; Casalongué, C. A.; Appl. Microbiol. Biotechnol. 2013, 97, 6957.

82. Goy, R. C.; Morais, S. T. B.; Assis, O. B. G.; Braz. J. Pharmacogn. 2016, 26, 122.

83. Elsabee, M. Z.; Abdou, E. S.; Sci. Eng. C 2013, 33, 1819.

84. Kakaei, S.; Shahbazi, Y.; LWT-Food Sci. Technol. 2016, 72, 432.

85. Mohan, C. O.; Ravishankar, C. N.; Lalitha, K. V.; Srinivasa Gopal, T. K.; Food Hydrocolloids 2012, 26, 167.

86. Nowzari, F.; Shábanpour, B.; Ojagh, S. M.; Food Chem. 2013, 141, 1667.

87. Tayel, A. A.; Moussa, S.; Opwis, K.; Knittel, D.; Schollmeyer, E.; Nickisch-Hartfiel, A.; Int. J. Biol. Macromol. 2010, 47, 10.

88. Champer, J.; Patel, J.; Fernando, N.; Salehi, E.; Wong, V.; Kim, J.; AMB Express 2013, 3, 1.

89. Raven, P. H.; Evert, R. E.; Eichhorn, S. E.; Biologia Vegetal; Guanabara: Rio de Janeiro, RJ, 2014.

90. Hadwiger, L. A.; Plant Sci. 2013, 208, 42.

91. Lee, C. G.; Koo, J. C.; Park, J. K.; Plant Pathol. J. 2016, 32, 242. 
92. Lopez-Moya, F.; Suarez-Fernandez, M.; Lopez-Llorca, L. V.; Int. J. Mol. Sci. 2019, 20.

93. Limon, T.; Birke, A.; Monribot-Villanueva, J. L.; Guerrero-Analco, J. A.; Altúzar-Molina, A.; Carrión, G.; Goycoolea, F. M.; Moerschbacher, B. M.; Aluja, M.; J. Sci. Food Agric. 2020, jsfa. 10903.

94. Grande-Tovar, C. D.; Chaves-Lopez, C.; Serio, A.; Rossi, C.; Paparella, A.; Trends Food Sci. Technol. 2018, 78, 61.

95. Al-Najada, A. R.; Gherbawy, Y. A.; Food Biotechnol. 2015, 29, 166.

96. Meng, D.; Garba, B.; Ren, Y.; Yao, M.; Xia, X.; Li, M.; Wang, Y.; Int. J. Biol. Macromol. 2020, 158, 1063.

97. Guo, H.; Qiao, B.; Ji, X.; Wang, X.; Zhu, E.; Postharvest Biol. Technol. 2020, 161, 110883.

98. Liu, Y.; Sun, Z.; Xiu, L.; Huang, J.; Zhou, F.; J. Food Biochem. 2018, $42,1$.

99. Li, Y.; Chi, Y.-Q.; Yu, C.-H.; Xie, Y.; Xia, M.-Y.; Zhang, C.-L.; Han, X.; Peng, Q.; Carbohydr. Polym. 2020, 241, 116386.

100. Tsai, G.-J.; Zhang, S.-L.; Shieh, P.-L.; J. Food Prot. 2004, 67, 396.

101. Andres, Y.; Giraud, L.; Gerente, C.; Le Cloirec, P.; Environ. Technol. 2007, 28, 1357.

102. Martins, A.; Facchi, S.; Follmann, H.; Pereira, A.; Rubira, A.; Muniz, E.; Int. J. Mol. Sci. 2014, 15, 20800.

103. Sizar, O.; Unakal, C. G.; Gram Positive Bacteria, StatPearls Publishing LLC, 2021.

104. Tsai, T.; Chien, H. F.; Wang, T. H.; Huang, C. T.; Ker, Y. B.; Chen, C. T.; Antimicrob. Agents Chemother. 2011, 55, 1883.

105. Moeini, A.; Pedram, P.; Makvandi, P.; Malinconico, M.; Gomez d'Ayala, G.; Carbohydr. Polym. 2020, 233, 115839.

106. Martins, A. F.; Vlcek, J.; Wigmosta, T.; Hedayati, M.; Reynolds, M. M.; Popat, K. C.; Kipper, M. J.; Appl. Surf. Sci. 2020, 502, 144282.

107. Machado, B. R.; Facchi, S. P.; de Oliveira, A. C.; Nunes, C. S.; Souza, P. R.; Vilsinski, B. H.; Popat, K. C.; Kipper, M. J.; Muniz, E. C.; Martins, A. F.; Int. J. Mol. Sci. 2020, 21, 1.

108. Madureira, A. R.; Pereira, A.; Castro, P. M.; Pintado, M.; J. Food Eng. 2015, 167, 210.

109. Caroni, J. G.; de Almeida Mattos, A. V.; Fernandes, K. R.; Balogh, D. T.; Renno, A. C. M.; Okura, M. H.; Malpass, A. C. G.; Ferraresi, C.; Garcia, L. A.; Sanfelice, R. C.; Pavinatto, A.; Polym. Bull. 2020.

110. Shepherd, R.; Reader, S.; Falshaw, A.; Glycoconj. J. 1997, 14, 535.

111. Weinhold, M. X.; Sauvageau, J. C. M.; Keddig, N.; Matzke, M.; Tartsch, B.; Grunwald, I.; Christian, K. 2009, 498.

112. Teng, D. In Chitosan-Based Hydrogels; Yao, K., Li, J., Yao, F., Yin, Y., eds.; CRC Press: Boca Raton, 2011; p. 38.

113. Yuan, Y.; Chesnutt, B. M.; Haggard, W. O.; Bumgardner, J. D.; Materials (Basel). 2011, 4, 1399.

114. Cardoso, M. B.; Signini, R.; Campana-Filho, S. P.; Polym. Bull. 2001, 47, 183.

115. Matica, M. A.; Aachmann, F. L.; Tøndervik, A.; Sletta, H.; Ostafe, V.; Int. J. Mol. Sci. 2019, $20,1$.

116. Agnihotri, S. A.; Mallikarjuna, N. N.; Aminabhavi, T. M.; J. Control. Release 2004, 100, 5.

117. Ravi Kumar, M. N. .; React. Funct. Polym. 2000, 46, 1.

118. Facchinatto, W. M.; dos Santos, D. M.; Fiamingo, A.; Bernardes-Filho, R.; Campana-Filho, S. P.; de Azevedo, E. R.; Colnago, L. A.; Carbohydr. Polym. 2020, 250, 116891.

119. Shigemasa, Y.; Matsuura, H.; Sashiwa, H.; Saimoto, H.; Int. J. Biol. Macromol. 1996, 18, 237.

120. Kumirska, J.; X., M.; Czerwicka, M.; Kaczyski, Z.; Bychowska, A.; Brzozowski, K.; Thming, J.; Stepnowski, P.; Mar. Drugs 2010, 8, 1567.

121. Kulikov, S. N.; Lisovskaya, S. A.; Zelenikhin, P. V.; Bezrodnykh, E. A.; Shakirova, D. R.; Blagodatskikh, I. V.; Tikhonov, V. E.; Eur. J. Med. Chem. 2014, 74, 169.

122. Mellegård, H.; Strand, S. P.; Christensen, B. E.; Granum, P. E.; Hardy, S. P.; Int. J. Food Microbiol. 2011, 148, 48.
123. Yuan, Y.; Chen, L.; Shi, W.; Wang, Z.; Zhang, H.; Molecules 2020, 25, 4074.

124. Byun, S. M.; No, H. K.; Hong, J. H.; Lee, S. Il; Prinyawiwatkul, W.; Int. J. Food Sci. Technol. 2013, 48, 136.

125. Jung, E. J.; Youn, D. K.; Lee, S. H.; No, H. K.; Ha, J. G.; Prinyawiwatkul, W.; Int. J. Food Sci. Technol. 2010, 45, 676.

126. Tayel, A. A.; Moussa, S.; El-Tras, W. F.; Knittel, D.; Opwis, K.; Schollmeyer, E.; Int. J. Biol. Macromol. 2010, 47, 454.

127. Chien, R. C.; Yen, M. T.; Mau, J. L.; Carbohydr. Polym. 2016, 138, 259.

128. Grobler, S. R.; Mater. Sci. Eng. Adv. Res. 2018, 2, 27.

129. Mehrabi, M.; Montazeri, H.; Dounighi, M. N.; Rashti, A.; VakiliGhartavol, R.; Arch. Razi Inst. 2018, 73, 165.

130. Zheng, L. Y.; Zhu, J. F.; Carbohydr. Polym. 2003, 54, 527.

131. Garcia, L. G. S.; Guedes, G. M. de M.; da Silva, M. L. Q.; CasteloBranco, D. S. C. M.; Sidrim, J. J. C.; Cordeiro, R. de A.; Rocha, M. F. G.; Vieira, R. S.; Brilhante, R. S. N.; Carbohydr. Polym. 2018, 195, 662.

132. Garcia, L. G. S.; de Melo Guedes, G. M.; Fonseca, X. M. Q. C.; PereiraNeto, W. A.; Castelo-Branco, D. S. C. M.; Sidrim, J. J. C.; de Aguiar Cordeiro, R.; Rocha, M. F. G.; Vieira, R. S.; Brilhante, R. S. N.; Int. J. Biol. Macromol. 2020, 143, 341.

133. Severino, R.; Ferrari, G.; Vu, K. D.; Donsì, F.; Salmieri, S.; Lacroix, M.; Food Control 2015, 50, 215.

134. Li, Z.; Yang, F.; Yang, R.; Int. J. Biol. Macromol. 2015, 75, 378.

135. Kaya, M.; Asan-Ozusaglam, M.; Erdogan, S.; J. Biosci. Bioeng. 2016, $121,678$.

136. Bano, I.; Ghauri, M. A.; Arshad, M.; Yasin, T.; Younus, M.; Microb. Drug Resist. 2017, 23, 958.

137. Tokura, S.; Ueno, K.; Miyazaki, S.; Nishi, N.; New Macromolecular Architecture and Functions, $2^{\text {nd }}$ ed., Springer: Berlin, Heidelberg, 1996.

138. Kong, M.; Chen, X. G.; Liu, C. S.; Liu, C. G.; Meng, X. H.; Yu, L. J.; Colloids Surfaces B Biointerfaces 2008, 65, 197.

139. Kulikov, S. N.; Tikhonov, V. E.; Bezrodnykh, E. A.; Lopatin, S. A.; Varlamov, V. P.; Russ. J. Bioorganic Chem. 2015, 41, 57.

140. Kim, S.; Rajapakse, N.; Carbohydr. Polym. 2005, 62, 357.

141. Fernández-Pan, I.; Maté, J. I.; Gardrat, C.; Coma, V.; Food Hydrocoll. 2015, 51, 60.

142. Laokuldilok, T.; Potivas, T.; Kanha, N.; Surawang, S.; Seesuriyachan, P.; Wangtueai, S.; Phimolsiripol, Y.; Regenstein, J. M.; Food Biosci. 2017, $18,28$.

143. Dotto, G. L.; Vieira, M. L. G.; Pinto, L. A. A.; LWT-Food Sci. Technol. 2015, 64, 126.

144. Chang, S. H.; Lin, H. T. V.; Wu, G. J.; Tsai, G. J.; Carbohydr. Polym. 2015, 134, 74.

145. Wang, W.; Meng, Q.; Li, Q.; Liu, J.; Zhou, M.; Jin, Z.; Zhao, K.; Int. J. Mol. Sci. 2020, 21, 487.

146. Verlee, A.; Mincke, S.; Stevens, C. V.; Carbohydr. Polym. 2017, 164, 268.

147. Pavinatto, A.; Fiamingo, A.; Bukzem, A. D. L.; Silva, D. S.; Santos, D. M.; Senra, T. A. D.; Facchinatto, W. M.; Campana Filho, S. P. In Frontiers in Biomaterials; Pavinatto, A., Fiamingo, A., Bukzem, A. de L., de Souza e Silva, D., dos Santos, D. M., Senra, T. A. D., Facchinatto, W. M., Campana-Filho, S. P., eds.; Bentham Science Publishers: Al Sharjah, 2017; Vol. 3, pp. 107.

148. Freitas, E. D.; Moura, C. F.; Kerwald, J.; Beppu, M. M.; Polymers (Basel) 2020, 12, 1.

149. Campana Filho, S. P.; Signini, R.; Cardoso, M. B.; Processos Químicos 2007, 1,9 .

150. Silva, H. S. R. C.; Santos, K. S. C. R. dos; Ferreira, E. I.; Quim. Nova 2006, 29, 776.

151. Li, J.; Zhuang, S.; Eur. Polym. J. 2020, 138, 109984.

152. Qin, Y.; Li, P.; Guo, Z.; Carbohydr. Polym. 2020, 236, 116002.

153. Buzón-Durán, L.; Martín-Gil, J.; Marcos-Robles, J. L.; FombellidaVillafruela, Á.; Pérez-Lebeña, E.; Martín-Ramos, P.; Agronomy 2020, 10. 
154. dos Santos, D. M.; de Lacerda Bukzem, A.; Campana-Filho, S. P.; Carbohydr. Polym. 2016, 138, 317.

155. Xu, Y.; Zhang, H.; Liu, X. W.; J. Org. Chem. 2021, 85, 15827.

156. Rúnarsson, Ö. V.; Holappa, J.; Nevalainen, T.; Hjálmarsdóttir, M.; Järvinen, T.; Loftsson, T.; Einarsson, J. M.; Jónsdóttir, S.; Valdimarsdóttir, M.; Másson, M.; Eur. Polym. J. 2007, 43, 2660.

157. Bakshi, P. S.; Selvakumar, D.; Kadirvelu, K.; Kumar, N. S.; React. Funct. Polym. 2018, 124, 149.

158. Follmann, H. D. M.; Martins, A. F.; Nobre, T. M.; Bresolin, J. D.; Cellet, T. S. P.; Valderrama, P.; Correa, D. S.; Muniz, E. C.; Oliveira, O. N.; Carbohydr. Polym. 2016, 137, 418.
159. Fan, Z.; Qin, Y.; Liu, S.; Xing, R.; Yu, H.; Chen, X.; Li, K.; Li, P.; Carbohydr. Polym. 2018, 190, 1.

160. Rahimi, M.; Ahmadi, R.; Samadi Kafil, H.; Shafiei-Irannejad, V.; Mater. Sci. Eng. C 2019, 101, 360.

161. Li, J.; Zhao, L.; Wu, Y.; Rajoka, M. S. R.; Colloids Surf., B 2019, 173, 429.

162. Signini, R.; Filho, S. P. C.; Polímeros 1998, 8, 63.

163. Dodane, V.; Vilivalam, V. D.; Pharm. Sci. Technol. Today 1998, 1, 246. 164. Ardila, N.; Daigle, F.; Heuzey, M. C.; Ajji, A.; Molecules 2017, $22,1$. 165. Tsai, G. J.; Su, W. H.; J. Food Prot. 1999, 62, 239.

166. Ma, Z.; Garrido-Maestu, A.; Jeong, K. C.; Carbohydr. Polym. 2017, 176, 257. 